\title{
Working
}

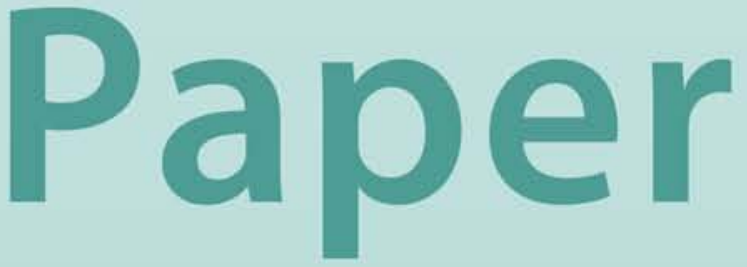




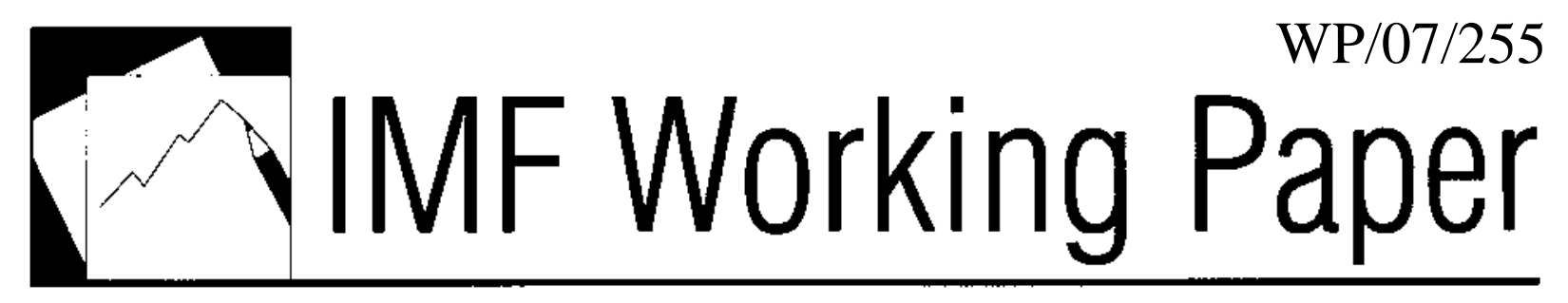

Mainstreaming Statistics in the Poverty Reduction Strategy Approach to Provide for More Effective Technical Assistance: Some Experience at the IMF

Robin D. Kibuka 


\title{
IMF Working Paper
}

\author{
Statistics Department
}

\section{Mainstreaming Statistics in the Poverty Reduction Strategy Approach to Provide for More Effective Technical Assistance: Some Experience at the IMF}

\author{
Prepared by Robin D. Kibuka
}

November 2007

\begin{abstract}
This Working Paper should not be reported as representing the views of the IMF. The views expressed in this Working Paper are those of the author and do not necessarily represent those of the IMF or IMF policy. Working Papers describe research in progress by the author(s) and are published to elicit comments and to further debate.

The paper reviews the Poverty Reduction Strategy (PRS) approach and efforts to build institutional statistical capacity to permit evidence-based monitoring of the Poverty Reduction Strategy Papers (PRSPs). Integrating the PRS approach and statistical development strategies could provide significant synergies in improving the monitoring of the PRSP goals. Mainstreaming the statistical strategies in such development plans should enhance the national priority for statistical reforms and provide a basis for costing such reforms for their incorporation into the medium-term expenditure framework. The paper concludes that such an outcome is likely to facilitate funding for the implementation of these reforms and boost the effectiveness of statistical technical assistance.

JEL Classification Numbers: C82, E6, F35, H41, H5, I32, O1

Keywords: PRSP, statistical strategies, evidence-based monitoring, MTEF, technical assistance

Author’s E-Mail Address: rkibuka@imf.org

This paper benefited from comments from William E. Alexander, Elliott Harris, Kevin O’Connor, Tom Morrison, Steve Kayizi, John Cady, Andrew Kitili, Meshack Tjirongo, and Jaroslav Kuceera, as well as from colleagues in a number of IMF and World Bank departments. Ken Kirkley provided useful technical assistance. Comments on an earlier draft were received from participants in the Scientific Statistics Conference in Kampala, Uganda during June 11-13, 2007.
\end{abstract}




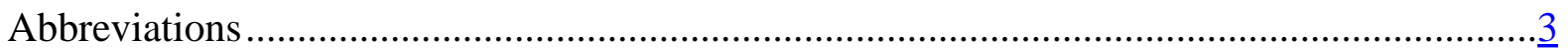

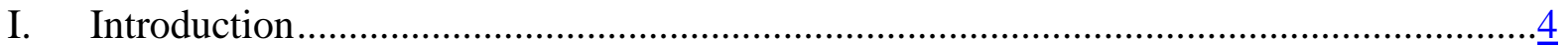

II. Development Strategies, the PRS Approach, and the Demand for Data .........................

III. Parallel Developments in Statistical Strategies....................................................... 12

IV. Converging Development and Statistical Strategies...............................................17

V. Constraints to Effective Statistical Technical Assistance ..........................................19

VI. Realistic Budget for Statistical Reforms ............................................................ 4

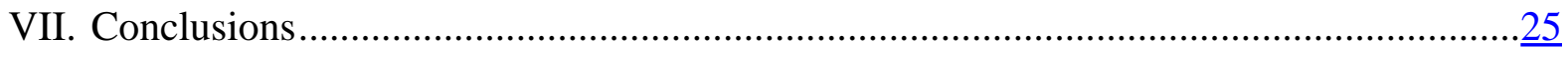

Table

1. Adequacy of Resources for Statistical Production in PRGF-Eligible Countries.............20

Figure

1. Links Between the GDDS, the DQAF/ROSC, the PRSP, the PRGF, and the NSDS ..... 14

Boxes

1. Development Strategies, Aid to Developing Countries, and IMF Programs..................... $\underline{5}$

2. IMF Independent Evaluation Office Evaluation of the IMF's Role in the PRSPs and the PRGF ..........................................................................................

3. Essential Features and Issues in PRSP Monitoring (Based on a 12-Country

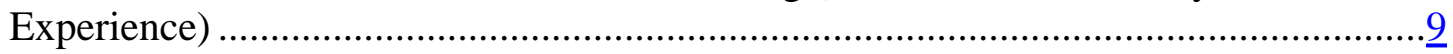

4. 2005 IMF/World Bank Staff Review of the PRSP Approach ….................................10

5. Select Major Statistical Development Initiatives.......................................................13

Appendices

I. Paris Declaration on Aid Effectiveness: Indicators of Progress ..................................27

II. Data Quality Assessment Framework-Generic Framework.................................... 28

III. GDDS-Anglophone Africa DFID Project.............................................................. 31

IV. GDDS/PRSP Module: Improving Planning and Execution of Statistical

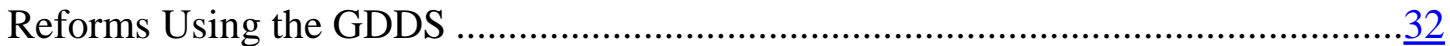

V. Template for Costing and Integrating a Statistical Development Action Plan

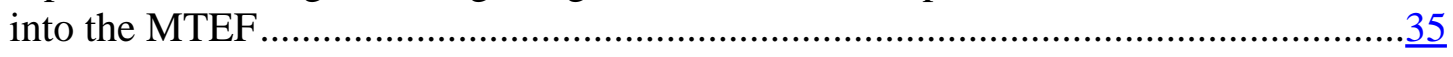

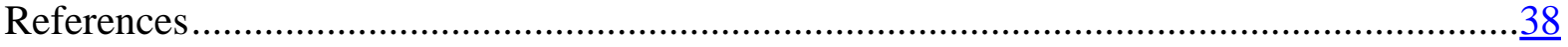


AfDB

COFOG

DFID

DQAF

GDDS

GFSM 2001

HIPC

IDA

ISTEBU

JSA

LICs

MAPS

MDGs

MDRI

MTEF

NSDS

PARIS21

PER

PRGF

PRS

PRSP

ROSC

SDDS

SWAp

TA
African Development Bank

Classification of Functions of Government

United Kingdom's Department for International Development

Data Quality Assessment Framework

General Data Dissemination System

Government Finance Statistics Manual 2001

Heavily indebted poor countries

International Development Association

Institut de Statistique et des Etudes Economiques du Burundi

Joint staff assessment

Low-income countries

Marrakech Action Plan for Statistics

Millennium Development Goals

Multilateral Debt Relief Initiative

Medium-term expenditure framework

National Strategy for the Development of Statistics

Partnership in Statistics Development in the $21^{\text {st }}$ Century

Public expenditure review

Poverty Reduction and Growth Facility

Poverty Reduction Strategy

Poverty Reduction Strategy Paper

Report on the Observance of Standards and Codes

Special Data Dissemination Standard

Sector-Wide Approach

Technical assistance 


\section{Mainstreaming Statistics in the PRS Approach to Provide for More Effective TECHNICAL AsSISTANCE: SOME EXPERIENCE AT THE IMF}

\section{INTRODUCTION}

The paper makes the case that while the Poverty Reduction Strategy (PRS) approach ${ }^{1}$ has emerged as a powerful vehicle for mobilizing and focusing nationally owned broad-based efforts and resources to grow out of poverty, it still lags in its capacity to monitor these desirable objectives effectively. Part of the problem is that developing the requisite institutional statistical capacity to permit evidence-based monitoring of the Poverty Reduction Strategy Paper (PRSP) goals has not been integral to, and therefore has not moved in step with, the advances in the design and implementation of the PRSPs. An emerging lesson is that integrating the PRS approach and statistical development strategies could provide significant synergies in improving the monitoring of the PRSP goals, while enhancing the effectiveness of statistical capacity building.

Notwithstanding the focus on PRSPs, the approach has broader applications for countries that have not adopted PRSPs formally but engage in some form of national planning or strategies for development. Arrangements to mainstream ${ }^{2}$ the statistical strategies in such development plans, as in the case of the PRSP, should enhance the national priority for statistical reforms and thus provide a basis for costing such reforms for incorporating them into the mediumterm expenditure framework (MTEF). ${ }^{3}$ This paper argues that such an outcome is also likely to facilitate the implementation of these reforms and boost the effectiveness of statistical technical assistance (TA) by creating an environment conducive to sustained transfer of expertise to local officials.

\footnotetext{
${ }^{1}$ The approach entails preparation of nationally owned comprehensive poverty reduction strategy papers, which can also be used by donors and other development partners for providing assistance to low-income countries (see Box 1).

${ }^{2}$ The terms "integration" and mainstreaming” statistics into the PRS approach are used interchangeably in this paper. They refer to the process of designing/developing all aspects of the PRS approach concurrently and in a fully coordinated manner with the relevant statistical issues, including the requisite statistical capacity building to ensure the availability of data to monitor progress and inform policies. This should ultimately require a clear identification also of the cost of the essential statistical reforms to implement the PRS approach. In practical terms, the costing and inclusion of statistical reform in the budget has serious implications for the implementation of such reforms and the effectiveness of technical assistance, hence, the emphasis placed on this issue in the paper.

${ }^{3}$ MTEF is used throughout this paper to refer also to the medium-term macroeconomic framework.
} 
Box 1. Development Strategies, Aid to Developing Countries, and IMF Programs

\begin{tabular}{l} 
Major Initiative \\
\hline Poverty Reduction Strategy Paper (PRSP): Introduced by the IMF and the \\
World Bank to strengthen their work in low-income countries (LICs), including \\
through enhanced new financial assistance and debt relief. PRSPs are nationally \\
owned and developed through a broad participatory process to spell out a \\
comprehensive strategy to reduce poverty and provide a common basis for donor \\
and other international support.
\end{tabular}

Poverty Reduction and Growth Facility (PRGF): Launched by the IMF to replace the enhanced structural adjustment facility and provide emphasis on poverty reduction in LIC programs. PRGFs are framed around the PRSP as basis for concessional lending to LICs and debt relief under the joint (with the World Bank) Heavily Indebted Poor Countries (HIPC) Initiative. Since 2005, debt relief is also provided under the Multilateral Debt Relief Initiative (MDRI), with somewhat different qualification criteria.

The Millennium Development Goals (MDGs): Established at the United Nations Millennium Summit by world leaders on eight specific and measurable development goals to be achieved by 2015. The first seven goals focus on eradicating extreme poverty and hunger; achieving universal primary education; promoting gender equality and empowering women; reducing child mortality; improving maternal health; combating HIV/AIDS, malaria, and other diseases; and ensuring environmental sustainability. The eighth goal calls for creating a global partnership for development, with targets for aid, trade, and debt relief.

Monterrey Consensus: Summit-level meeting, with active participation by the IMF, World Bank, and World Trade Organization (WTO), and representatives of the business sector and civil society was convened by the United Nations in Mexico. A significant step toward meeting the MDGs was taken with the adoption of a two-pillar strategy, whereby sustained pursuit of sound policies and good governance by the LICs is to be matched by larger and more effective international support.

Paris Declaration on Aid Effectiveness: Statement of resolve by ministers of developed and developing countries responsible for promoting development and heads of multilateral and bilateral development institutions to take far-reaching and monitorable actions to reform the ways they deliver and manage aid as they looked ahead to the UN five-year review of the MDGs later in 2005.

An even more powerful argument for enhancing the role of statistics in the PRS approach is the growing recognition that monitoring can improve the development effectiveness of any intervention, including donor aid, and that monitoring requires data with a high degree of accuracy and integrity. This line of argument underlies the Managing for Development Results Agenda and the Paris Declaration on Aid Effectiveness (for details, see below), which have been adopted by partner countries and donors and is therefore not elaborated in the paper. The focus remains on the practical aspects of using TA more effectively to achieve the desired ends, including an adequate statistical system. 


\section{DeVelopment Strategies, the PRS APPROACH, AND THE DEMAND FOR DATA}

With the launching of the PRSP framework in 1999, the IMF and the World Bank set in motion major changes in the international community's approach to dealing with development strategies. A major change focused on poverty reduction centered on countryowned strategies. As summarized in Box 1, the other major developments in this regard were the adoption of the Millennium Development Goals (MDGs), the Monterrey Consensus, and the Paris Declaration on Aid Effectiveness.

The growing importance of the PRS approach is reflected by the fact that, as of July 2007, 45 countries had prepared PRSPs, while 12 countries had prepared interim PRSPs. Eleven countries comprising Benin, Burkina Faso, Ghana, Madagascar, Mauritania, Mozambique, Nicaragua, Senegal, Tanzania, Uganda, and Vietnam had already implemented their original PRSPs and adopted a second-generation PRSP.

A central theme underlying these development strategies is the focus on objectives, goals, and targets that are mainstreamed in country-owned poverty reduction strategies. As such, they all require a substantial amount of macroeconomic and sociodemographic statistics, which have to be compiled largely by the LICs themselves. Along the way (and this is most evident in the Paris Declaration), the international community also focused on the need for effective monitoring of progress in reducing poverty, implying a second wave of data and information requirements. These data would help establish benchmarks against which to measure progress and numerous intermediate markers to help quantify or give a sense of magnitude of change over time (see World Bank, 2004 and, since 2004, The Global Monitoring Report available at http://worldbank.org/website/external/extdec/extglobalmonitor).

Another important component of the increased demand for statistics has to do with policymakers' needs to inform sound economic policies. While these needs predate the PRS approach, the introduction of the latter accelerated the data requirements to broaden the design and implementation of macroeconomic and development policies that directly incorporate a central role of poverty reduction.

This substantial growth in the demand for statistics exacerbated the pressure on the LICs' statistical systems - already short on resources - to undertake extensive surveys (e.g., on poverty, gender issues, household income and expenditure, specific sectors) and censuses to generate the requisite source data to compile and disseminate substantial datasets that are internationally comparable, of high quality, and available in a timely manner.

An integral part of the strategy to reduce poverty and foster economic development has been debt relief for the LICs. The three major initiatives, namely the Heavily Indebted Poor Countries (HIPC) Initiative; the Enhanced HIPC Initiative; and the Multilateral Debt Relief 
Initiative (MDRI), along with the related debt sustainability exercises and documentation, ${ }^{4}$ have also spawned additional significant data requirements from LICs, further straining their limited capacity.

In developing the PRS approach and other development strategies, the international collaborators focused mainly on the end objective. The major breakthrough to reach a consensus on the MDGs could not be translated easily into action to monitor progress toward these objectives. It required time to come to grips with the scope of the work entailed and develop the benchmarks and tools to measure progress. Indeed, while efforts were made to include monitoring and evaluation components in the early PRSPs and interim PRSPs, the process was largely ad hoc and, with hindsight, has proven to have been inadequate. Only with experience did the emphasis gradually expand to embrace also (1) comprehensive monitoring processes and the need to develop and integrate capacity building for statistics into the developing strategies and (2) the need to provide for the production and dissemination of the requisite data and information. The various evaluations of the PRS approach and the IMF support to members' programs bear this out as summarized in three evaluations in Boxes 2-4.

Notwithstanding the fact that these three evaluations of the PRS approach were either unlinked and/or independently established and implemented, they had some common aspects $^{5}$ and, to some extent, overlapped on the content and country coverage. They reached broadly the same conclusions - mainly that while some progress has been made, much remains to be done to mainstream monitoring systems into the PRSP and integrate them with policy analysis and decision making. The needs differ among countries, but one of the evaluations notes specifically that Africa faces a particularly more difficult challenge in terms of a lower starting point and the progress made thus far. All three evaluations underpin the critical importance of linking the PRSPs to the budget process, in particular, the MTEF with appropriate costing of the reforms and their prioritization for resource allocation purposes. ${ }^{6}$ Capacity building for national institutions is stressed, noting, in particular, the need to avoid duplication of statistical systems and ensuring full harmonization with donor requirements and procedures.

\footnotetext{
${ }^{4}$ In the case of the HIPC and Enhanced HIPC Initiative, the decision point and completion point documents are required as a basis for the decisions of the IMF and World Bank Executive Boards. The MDRI also requires Executive Board documentation. For details, see http://www.imf.org/external/np/exr/facts/hipc.htm, http://www.imf.org/external/np/exr/facts/mdri.htm, and IMF, 2007a.

5 The IMF's Independent Evaluation Office report in Box 1 focuses exclusively, while the Joint Bank/Fund reviews partially cover, the role of the IMF. The review in Box 3 was undertaken jointly by DFID and World Bank staff, drawing on the experience of 12 LICs to focus on the institutional arrangements, that is, formal and informal processes, procedures, rules, and mechanisms that bring monitoring activities into a coherent framework.

${ }^{6}$ For a more comprehensive coverage, see World Bank and GTZ, 2007.
} 


\section{Box 2. IMF Independent Evaluation Office's Evaluation of the IMF's Role in the PRSPs and the PRGF}

- The focus of most PRSPs is on the composition of public expenditure, especially social sector spending, with much less emphasis on other aspects of a broader strategy to encourage povertyreducing growth. "Even in the area of public expenditure, the operational value of PRSPs is often limited because of the still rudimentary nature of most costing and prioritization...." Capacity constraints have been a severe impediment to progress in implementing the PRS approach. Insufficient attention has been paid to developing a systematic plan of action to strengthen capacity, including in the IMF's area of primary competence.

- "PRSs that substantially meet the goals set out in the original policy papers require considerable technical and analytical capacities, not to mention financial support. However, in the current setting, nothing ensures that capacity-strengthening priorities of countries will be addressed, and the link with lending decisions can be ambiguous....”

- $\quad$ PRSP contents reflect value added over previous strategies in terms of comprehensiveness, results orientation, and long-term perspective, although significant scope for progress remains even in "good practice" cases. The analytic bases of PRSPs are typically weak, most notably with regard to the macroeconomic framework and policies to promote growth. Insufficient prioritization, inadequate costing, and a tendency to avoid controversial structural reform issues mean that PRSPs do not yet provide an adequate framework for making strategic decisions on key trade-offs.

- A frequent problem revealed by our case studies is that the indicators and monitoring arrangement contemplated in the PRSPs far exceed the underlying data capacity to collect and analyze the underlying data — a process that is very resource-intensive and, realistically, will take many years to institutionalize in most countries. Furthermore, indicators are typically better defined for health and education strategies than in other areas, where inputs or process-based indicators tend to dominate, or indicators are simply lacking (e.g., structural reforms or governance).

- The most important obstacle to a greater results orientation of PRSPs is the still tenuous nature of links to the budget and MTEF. Over half of the full sample of PRSPs lacked such links initially. Where links between the PRSP and the MTEF existed on paper from the start, their effectiveness was weakened by the fact that the MTEF was itself only loosely connected with the budget actually implemented. These weaknesses reflect a combination of limited costing and prioritization in the PRSP and the poor state of public expenditure management generally.

- Joint Staff Assessment (JSA) papers (prepared by IMF and World Bank staff) identify costing, financing, and prioritization as one of the main weaknesses of the PRSPs in two thirds of the 23 cases. Costing of action plans is frequently attempted, but is usually partial and rudimentary. Over a third of PRSPs lack a financing plan and/or a prioritized action plan. Often, prioritization and costing are more advanced in "priority areas" (typically health, education, and infrastructure) than in other areas.

- The obstacles (to "mainstreaming poverty and social impact analysis") most often cited in internal reviews were data limitations and national capacity constraints. Both are undoubtedly important, but they should not be overstated....it is possible to assess some of the poverty even in countries with limited data.

Source: IMF (2004). 


\section{Box 3. Essential Features and Issues in PRSP Monitoring (Based on a 12-Country Experience)}

- The development of a monitoring system is critical to a successful PRS. Such a system is intended both as a way of ensuring continuous improvement of the PRS and as an instrument of influencing the nature of the development policy process by making it more evidence-based and results-oriented.

- $\quad$ The system should track overall progress in poverty reduction against national targets and international measures of development success, such as MDGs, through the periodic measurement of selected indicators. This focuses on monitoring impact indicators and is accomplished by using administrative data as well as surveys, censuses, and quantitative and qualitative data and is usually led by the national statistics agencies.

- The case studies demonstrate that progress in establishing effective PRS monitoring systems has been limited. Few systems have created functioning links between monitoring and decision making. Organizing coordinated monitoring systems and ensuring that monitoring data are used in the policy process are both proving major practical challenges.

- Information on poverty outcomes and implementation can be used only to improve strategies and intervention when these outcomes are associated with cost and resource requirements. Expenditure tracking depends upon parallel progress in budget and public expenditure management reforms and availability of quality and timely data.

- Involving national statistical agencies is important because they are often the relatively most institutionally advanced elements in PRS monitoring systems. The systems arrangement must ensure complementarity with existing systems and statistical planning so as to avoid duplication....In addition, PRS monitoring systems should ensure that statistics agencies have sufficient resources and mandates to play their role in setting standards, undertaking the requisite surveys and censuses, providing technical assistance, and building the capacity of other national agencies. This may help increase the compatibility and complementarity of the data supplied by numerous agencies.

- $\quad$ The alignment of donor monitoring and reporting requirements around the national PRS monitoring systems remains at an early stage of development. Most donors do not seem to find annual progress reports sufficient for their own accountability and management purposes both because of quality concerns ....... Therefore donors tend to incorporate a separate monitoring and evaluation system in each of their individual projects leading to duplication of efforts and spreading resources thinly.

- $\quad$ Care should be taken in designing a PRS monitoring system to ensure complementarity with the development of the statistical systems. In practice, this lack of complementarity may be partly the result of the existing funding modalities for statistical systems. National statistical agencies tend to prioritize statistical operations for which donor funding is readily available, leaving little time for other functions. To remedy this, donors may need to consider more flexible ways of supporting the institutional development of national statistics agencies, such as through basket funding.

- $\quad$ Effective systems for monitoring a PRS must build demand for monitoring while organizing the supply side. Unless decision makers actively seek evidence to support policymaking and program management, monitoring practices are unlikely to hold across government administration.

- $\quad$ Creating a link between the PRS and the budget process is a critical objective for the PRS monitoring system. The need to access public resources creates powerful incentives across all public agencies and provides the most promising hook for creating demand for effective monitoring.... This is more readily accomplished in countries that have successfully introduced an MTEF. While the PRS sets down the general objectives and priorities, it is usually the MTEF that provides the framework within which explicit spending choices and trade-offs are made; it therefore represents the ideal opportunity to use monitoring information.

Source: Bedi and others, 2006. 


\section{Box 4. 2005 IMF/World Bank Staff Review of the PRSP Approach}

- The PRS approach is intended to serve as a platform for balanced and mutual accountability. This requires sufficiently specific operational plans that support PRS implementation and donor alignment. It also requires that aid be provided in support of the priorities set out in the PRSP in ways that reinforce, rather than detract from, domestic accountability....For countries, good practices include...improving the incentives and institutional arrangements for building and using PRS monitoring systems, and broadly disseminating monitoring results. Development partners can support the above practices by coordinated, demand-driven support for analytical work and capacity building; avoiding parallel monitoring systems; adapting their reporting requirements to allow more space to use country-specific instruments...

- Strengthening the link between the PRS and the budget process is essential to institutionalizing the PRS approach, ensuring that it is adapted to local circumstances, and helping countries better prioritize their strategies. More attention to costing the programs in PRSs, as well as alternative measures, also would facilitate this link. MTEFs can also help link the PRS to the budget process through greater clarity of objectives, predictability in allocation, and more comprehensive coverage and transparency in the use of funds...MTEFs and sector strategies can be mutually reinforcing. Well-developed sector strategies have facilitated the adoption of MTEFs, while drawing up sectoral MTEFs has helped to build capacity and foster expenditure planning. Drawing up sectoral MTEFs can help establish a comprehensive view of sector expenditures while better grounding sector strategies in budget realities. Gradually strengthening the linkage between the PRS and the MTEF by developing the MTEF sector by sector has worked well in a number of countries, such as Ghana, Georgia, Kyrgyz Republic, and Rwanda.

- Other initiatives of the PRS approach have strengthened the focus on results. This has created a substantial incremental demand for data, underscoring the need for effective national monitoring systems. However, significant challenges remain in developing well-coordinated monitoring systems with quality information that is accessible to various stakeholders.

- Although statistical capacity in International Development Association (IDA) countries has improved over the past five years, substantial improvements are still needed. Based on a diagnostic framework that considers three dimensions (1) statistical practice (the ability to adhere to internationally recommended standards and methods); (2) data collection (frequency of censuses/surveys and completeness of vital registration); and (3) indicator availability (availability and frequency of key socioeconomic indicators) some progress has been made between 1999 and 2005 along all threes dimensions. Of concern, though, is the limited improvement in data collection in all IDA countries, and in African countries in particular, the indicators reveal differences in the strengths and weaknesses of country systems, confirming that countrybased programs for capacity building will be needed to produce sustainable results.

- Progress in building monitoring systems that coordinate the collection of data, its analysis, and its use for policymaking has been limited in many countries. In fact, this is the area that joint staff advisory notes (JSANs), and, previously, JSAs most frequently mentioned as a significant constraint to PRS implementation The challenges on both supply and demand sides include (1) organizing a coordinated system; and (2) encouraging the actual use of information in the policy process... Only if the PRS is clearly prioritized and articulated can the PRS monitoring system be an effective way to improve accountability. Recognizing the centrality of effective monitoring systems, the World Bank’s Africa Action Plan indicates the Bank's willingness to assist all PRS countries in the region to develop and implement the monitoring and evaluation plans and to build integrated and evaluation systems.

- There may be several reasons why macroeconomic policy options have not been discussed more broadly in the PRS process. In some instances, macroeconomic policy decisions (e.g., the level of exchange rates or interest rates) are, by their nature, sensitive and cannot be made in a process of broad public debate. This is even the case in OECD countries. In other cases, governments are reluctant to discuss macroeconomic policy options in a broader public forum, as they consider this may slow decision making and complicate relations with donors. The institutional framework may also not be conducive to such discussions, and the necessary information may not be available on a timely basis and in accessible form. (See more details in paragraphs 66-69, pages 48-50.) 
With reference to the work of the IMF, two of the evaluations underline the focus of public expenditure on social sector spending and the better definition of the PRSP indicators and targets for the education and health strategies than for other areas. This emphasis on social sector issues is not surprising given the fact that it was already embedded in the design of the PRSP (IMF, 1999) with implications also for the Poverty Reduction and Growth Facility (PRGF) (since the former underpins the latter). However, this development has had, and continues to have, important ramifications for the PRS approach. First, the omission of statistics as a priority "sector" or thematic area-with a well-articulated comprehensive strategy and costed supporting reforms for incorporation in the MTEF for assured funding - is arguably a major contributory factor to the slow progress with monitoring in the PRSPs.

Second, within the statistical system, the relative neglect of macroeconomic data also stands out. $^{7}$ Two of the PRS approach evaluations note the typically weak analytical base, particularly with regard to the macroeconomic framework and policies to promote growth. The evaluators make the point also that a lack of timeliness of quality data in comparable and accessible form is impeding more open discussions of macroeconomic policy.

In summary, notwithstanding the large exogenous increase in demand for data created by the PRS approach, internal priority for statistical capacity and the implementation of the necessary reforms to ensure effective evidence-based monitoring has lagged. As a public good, statistics generate beneficial externalities, which add more value than the sum total for individual users in the market. Exploitation of the full potential of the public value of statistics, especially in the PRS approach, requires substantial advocacy and financing to better balance the external demand with the LICs' capacity to supply the requisite data-a form of market failure. Increased awareness on the part of policymakers is essential to convince them to assign greater priority and funding for statistics to ensure the desirable development of monitoring in the PRS approach. As evidenced by the adoption of the Paris Declaration and the message of the above reviews, the recognition of the value of data and monitoring has strengthened considerably, but it needs to reach certain key officials in LICs who can translate it into the still-elusive action.

While the response by the IMF, and indeed others, to the reviews above goes beyond the scope of this paper, it is important to note the ongoing efforts to strengthen the PRS approach. These endeavors are eclectic and cover a broad range of issues ranging from specific topics such as the role of the institution in LICs (see de Rato, 2006), ${ }^{8}$ the design of

\footnotetext{
${ }^{7}$ The issue is not the availability of data since many development partners have tended to generate the data they need, but rather the capacity of the LIC's statistical system to compile and disseminate a broad range of internally consistent data and metadata; the latter to inform users of any deficiencies in the data.

${ }^{8}$ See also http://www.imf.org/external/np/exr/ib/2005/092105.
} 
the PRGFs (IMF, 2007b), ${ }^{9}$ and data issues (IMF, 2005b) to broader issues covering the IMF's overall medium-term strategy (see IMF, 2005c, 2006a, and 2006b). A number of the other responses are related to the statistical strategies as detailed in Section III below.

\section{Parallel Developments in Statistical Strategies}

There was a parallel but independent formulation of comprehensive statistical development strategies at the IMF and elsewhere as summarized in Box 5. The General Data Dissemination System (GDDS), in particular, which preceded the PRSP, shares major elements with the latter. Both are, or broadly entail, institutional capacity-building frameworks (designed by the IMF and, to some extent, the World Bank -in the case of the GDDS) to accommodate country needs at various levels of development. They are both voluntary, country-owned, and are developed through broad-based participatory processes, although the participatory process is better institutionalized for the PRSP. Moreover, their elements broadly cover macroeconomic issues that tend to fall in the purview of the IMF and also cover socioeconomic issues that fall largely within the mandates of the World Bank and donors (Figure 1). The IMF Data Dissemination Standard Initiative comprising the GDDS and the Special Data Dissemination Standard (SDDS), as the name implies, focuses on the provision of data to the public in order to promote transparency. The SDDS focuses on the timely dissemination of a wide range of macroeconomic data and was designed for countries that either access or wish to access international capital markets. The GDDS was designed for countries lacking full statistical capacity, and is a broad framework providing objectives to which all countries can work over time to achieve a systemwide strengthening of their statistical capacity. Its focus is on developing comprehensive statistical frameworks and on promoting interagency collaboration (for details, see IMF, 1997). By design, the GDDS seeks to engage all participants in an active developmental process with regularly updated metadata and plans for improvement. These updates were also envisaged to be key links in the continuous identification, prioritization, and provision of TA to develop the statistical system. ${ }^{10}$

The GDDS was seen also as a means for progressing toward the SDDS for those countries that were interested in doing so and, indeed, there was expectation that some GDDS participants would, in due course, become SDDS subscribers. To date, six countries, namely, Armenia, Bulgaria, Kazakhstan, Kyrgyz Republic, Moldova, and Romania, have graduated

\footnotetext{
${ }^{9}$ See also http://www.imf.org/external/np/sec/pn/2005/pn05127.htm.

10 "The description of current practices (metadata) would correspond to each of the objectives for data, access, integrity, and quality dimensions in the GDDS. The plans (for improvement) would identify the major shortcomings relative to the objectives set out in the system (i.e., the GDDS); the steps by which the shortcomings would be addressed; the resources, including technical assistance, necessary to achieve the improvements; and the timeframe during which improvements would be achieved. In particular, the improvements to be undertaken within 3-5 years would be identified.” (IMF, 1997, p. 2)
} 


\begin{tabular}{|c|c|}
\hline \multicolumn{2}{|l|}{ Box 5. Select Major Statistical Development Initiatives } \\
\hline Initiative & Date \\
\hline $\begin{array}{l}\text { Special Data Dissemination Standard (SDDS): Launched in the wake of the emerging } \\
\text { economies crises of the mid-1990s by the IMF to set internationally accepted standards for } \\
\text { such economies to provide quality and timely economic and financial data to markets. The } \\
\text { objective was to encourage transparency and economic and financial policy discipline } \\
\text { among countries accessing international capital markets. This was seen as a way to help } \\
\text { reduce the volatility in capital flows, which were at the heart of the economic crises. } \\
\text { While subscription is voluntary, it comes with requirements to disseminate metadata and a } \\
\text { broad range of economic and financial data, which meet international standards, on the } \\
\text { national data dissemination page. Such data dissemination is based on advance release } \\
\text { calendars and meets specified periodicity and timeliness requirements. The IMF monitors } \\
\text { the SDDS requirements. }\end{array}$ & 1996 \\
\hline $\begin{array}{l}\text { General Data Dissemination System (GDDS): Launched by the IMF to help countries } \\
\text { which generally do not have access to international capital markets adopt a holistic } \\
\text { approach to developing their statistical systems. Participation is voluntary but participants } \\
\text { are expected to adhere to the dissemination of metadata, including plans for improvement } \\
\text { for specified economic, financial, and sociodemographic data categories to meet suggested } \\
\text { coverage, periodicity, and timeliness. }\end{array}$ & 1997 \\
\hline $\begin{array}{l}\text { PARIS21: The Partnership in Statistics Development in the } 21^{\text {st }} \text { Century was founded by } \\
\text { the OECD, the World Bank, the European Commission, the IMF, and the United Nations. } \\
\text { It was established in response to the UN Economic and Social Council resolution on the } \\
\text { goals of the UN Conference on Development to act as a catalyst for promoting a culture of } \\
\text { evidence-based policymaking and monitoring in all countries, and especially in } \\
\text { developing countries. The consortium is a partnership of policymakers, analysts, and } \\
\text { statisticians from all countries of the world. It focuses on promoting high-quality statistics, } \\
\text { making these data meaningful, and designing sound policies. The role of PARIS21 is to } \\
\text { foster more effective dialogue among those who produce development statistics and those } \\
\text { who use them, through facilitating international events, supporting country-based } \\
\text { activities, regional workshops, and subject matter task teams. }\end{array}$ & November 1999 \\
\hline $\begin{array}{l}\text { International Standards and Codes: Developed by several international organizations to } \\
\text { promote governance and transparency, and sound economic policies and practices. The } \\
\text { IMF collaborates with other international organizations to undertake missions to countries } \\
\text { to prepare Reports on the Observance of Standards and Codes (ROSCs), including data } \\
\text { ROSCs; the latter assesses data quality using the Data Quality Assessment Framework } \\
\text { (DQAF) and either the GDDS or the SDDS. The DQAF was developed by the IMF in } \\
\text { July } 2001 \text { (and updated in July 2003) to extend the dissemination standard/system to } \\
\text { incorporate a more comprehensive basis to assess the quality of data. It entails the } \\
\text { prerequisites for quality and five dimensions comprising assurances of integrity; } \\
\text { methodological soundness; accuracy and reliability; serviceability; and accessibility. }\end{array}$ & 2000 \\
\hline $\begin{array}{l}\text { Marrakech Action Plan for Statistics (MAPS): Launched following the Second } \\
\text { International Roundtable, Managing for Development Results in Morocco. Adopted } \\
\text { actions include (1) mainstreaming strategic planning of statistical development strategies } \\
\text { for all low-income countries by 2006, (2) undertaking urgent improvements needed for } \\
\text { MDG monitoring by 2005, and (3) increasing financing for statistical capacity building. }\end{array}$ & February 2004 \\
\hline $\begin{array}{l}\text { National Strategy for the Development of Statistics (NSDS): A major component of the } \\
\text { MAPS designed to improve the evidence-based “manage for results” by providing a } \\
\text { strategic framework for developing relevant poverty-focused statistics. The NSDS } \\
\text { approach has developed from existing initiatives such as the GDDS and borrows heavily } \\
\text { from the PRS processes. }\end{array}$ & 2004 \\
\hline
\end{tabular}


Figure 1. Links Between the GDDS, the DQAF/ROSC, the PRSP, the PRGF, and the NSDS

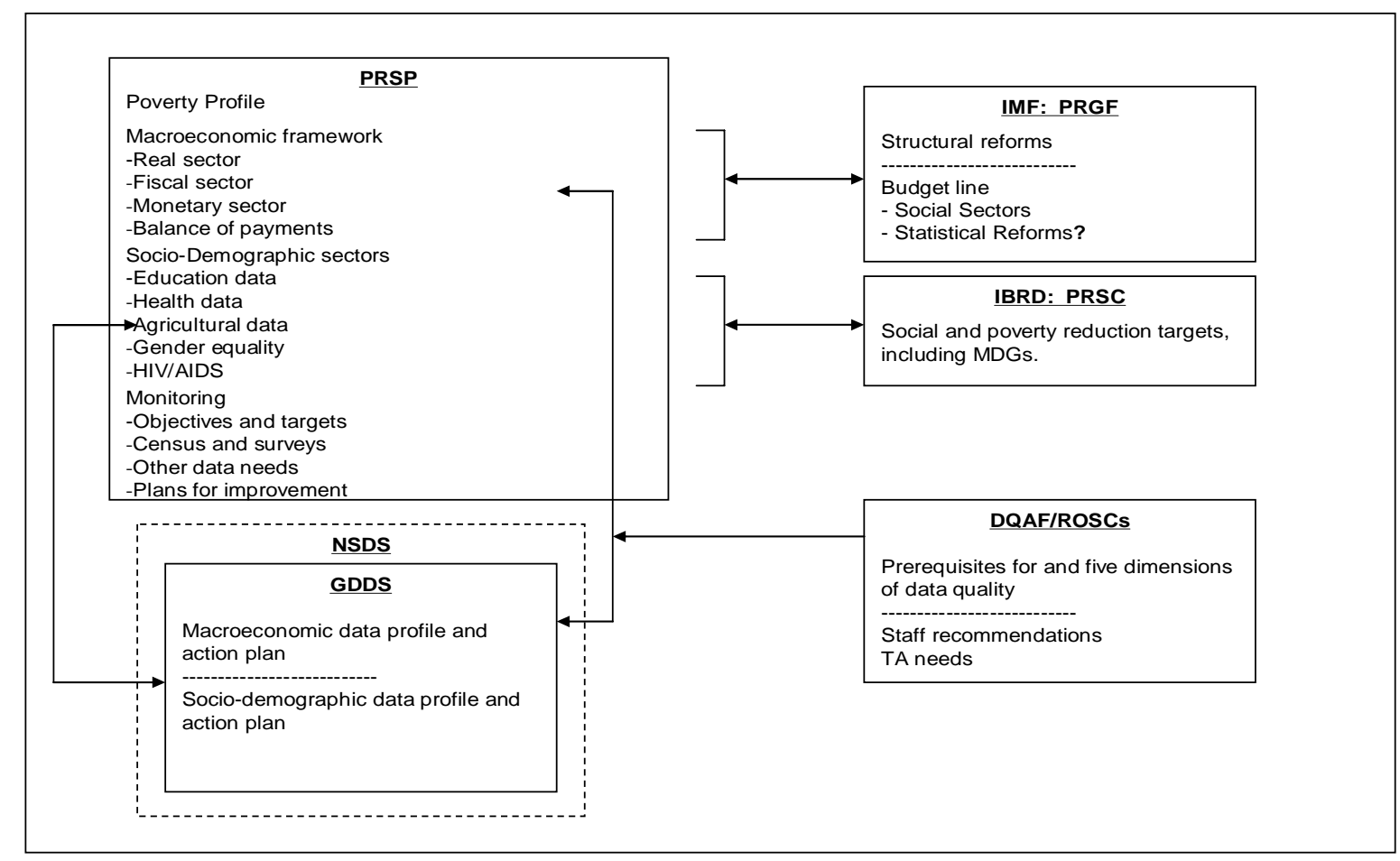


from the GDDS to the SDDS. Another important feature of the GDDS/SDDS dissemination initiative is its close link with the Data Quality Assessment Framework (DQAF) and the data module Report on the Observance of Standards and Codes (ROSC) process, through which the IMF undertakes comprehensive assessments of member countries' statistical systems in producing quality macroeconomic data consistent with international standards.

Consistent with the IMF's mandate on macroeconomic and financial policies and statistics, the institution has played a central role in developing the relevant international statistical standards. The four main sets of macroeconomic statistics comprise national accounts, balance of payments and international investment position, monetary and financial, and government finance statistics, all of which should be viewed as an integral system (for details, see IMF, 2007c). The standards for compiling statistics in these four areas are anchored in the System of National Accounts 1993 (1993 SNA), as it sets out the overarching conceptual framework for all macroeconomic statistics. These standards underpin the role of the IMF in fostering the development of internally consistent macroeconomic datasets for member countries - a prerequisite for the formulation of appropriate domestic policies. Moreover, such datasets are also comparable across countries and support the institution's surveillance role in an increasingly global economy.

The link between the data standards and the DQAF/ROSC reflects the historical developments in the IMF's response to the crises in emerging market countries of the 1990s. On data transparency issues, the first phase of this effort was the SDDS/GDDS dissemination initiative, ${ }^{11}$ followed by a more comprehensive second phase to further develop international best practice as a means of strengthening the global financial architecture, thus leading to broader data quality issues that go beyond the dissemination of data. ${ }^{12}$ These subsequent efforts led to the introduction of a more comprehensive framework for data quality, which could be used in assessing a member country's observance of standards and codes (the data ROSC), hence, the DQAF.

\footnotetext{
${ }^{11}$ The SDDS requirements are based on international best practice. IMF staff visited about 50 countries and had workshops, including many more to establish the periodicity and timeliness of the various indicators based on existing best international practice. The GDDS recommendations were based on "good practice" in developing countries, hence the range of such good practices that are specified.

${ }^{12}$ Standards and codes are benchmarks of good practices. The IMF and the World Bank have recognized international standards in 12 areas related to their work. In assessing countries' observance of these standards, and helping them implement reforms where needed, the IMF and the World Bank aim to improve the functioning of the economy as well as the basis for investors' decisions, and ultimately to promote greater financial stability and help prevent financial crises. The international standards in 12 areas may be divided into three groups, namely: (1) policy transparency, which includes data transparency (the SDDS, the GDDS, and, since July 2001, the DQAF); (2) financial sector regulation and supervision; and (3) market integrity. For details, see http://www.imf.org/external/np/exr/facts/sc.htm.
} 
Notwithstanding the emphasis of the GDDS on macroeconomic data issues - the central area of the IMF's mandate-the framework included also coverage of sociodemographic datasets that preoccupy most donor activities. This was done for two reasons: first, to recognize the importance of these datasets in the countries likely to join the GDDS, and second, not to infer that the macroeconomic data were more important than social data and possibly skew resources away from social data. The first IMF Executive Board meeting on the GDDS endorsed the inclusion of sociodemographic data, but some directors insisted that the IMF should not develop capabilities in this area and instead rely primarily on other international organizations. A United Nations Statistics Division (UNSD) staff member accompanied the IMF mission on the first pilot mission to produce GDDS metadata (July 1997) with a specific job to produce model sociodemographic metadata. The SDDS never included sociodemographic data since these were not relevant to the markets-oriented purpose of the SDDS; it was also assumed that the countries in the SDDS probably had acceptable sociodemographic data.

There has been good collaboration between the IMF and the World Bank and other organizations to develop sociodemographic data, metadata, and plans for their improvement in the GDDS. Some early data ROSC missions (e.g., to Senegal in 2002) were undertaken jointly with the World Bank and included assessments of the sociodemographic datasets and metadata. Efforts have been made also to develop DQAFs for the education, income, poverty, health, and population sectors, that is, to extend coverage to sociodemographic statistics. ${ }^{13}$

The National Strategy for the Development of Statistics (NSDS) — an important output of the Marrakech Action Plan for Statistics (MAPS) - builds around the GDDS ${ }^{14}$ and has been promoted mainly by the Partnership in Statistics Development in the $21^{\text {st }}$ Century (PARIS21) consortium of several international organizations. The NSDS focuses on a broader framework of a statistical system's development in fostering a wider strategic approach than the GDDS. While the GDDS focuses on outputs - the dissemination of metadata and timely quality data - the NSDS is input-oriented with a broader framework that encompasses infrastructure (e.g., office buildings, information technology systems, including supporting software packages, and other equipment), surveys and censuses, administrative data and information, long-term training, and data demand side issues - closely linked to data usage in policy analysis.

The broader perspective of the NSDS coincides with the mandates of the development banks and donors. These areas are attracting increased funding, including through the Trust Fund

\footnotetext{
${ }^{13}$ See http://siteresources.worldbank.org/INTISPMA/Resources/Training-Events.

${ }^{14}$ For details on how the GDDS is at the core of the NSDS, see PARIS21, 2004.
} 
for Statistical Capacity Building (funded by several donors) managed by the World Bank, STATCAP, ${ }^{15}$ and regional development banks, for instance, the African Development Bank (AfDB) and other donors. One operational area receiving welcome focus entails censuses (e.g., population and housing censuses), surveys, and administrative data recording systems. Much of this information and data are crucial to the PRSP process and provide mainly direct support for socioeconomic datasets. These censuses/surveys and improvements in administrative data also generate source data for the macroeconomic datasets and, thus, provide a vital link between the NSDS's broader aspirations and the more data-focused dissemination orientation of the GDDS.

\section{Converging DeVelopment ANd Statistical Strategies}

Earlier efforts to give greater impetus to statistical development in LICs focused on fostering broad frameworks and strategies outside of, but parallel to, the poverty reduction development strategies. However, an unmistakable trend has since evolved to mainstream statistical strategies into the development strategies, including the PRS approach. Examples include MAPS, the Paris Declaration, the outcome of the Third International Roundtable meeting in Hanoi (February 2007), and some work on African countries at the IMF. The two principal reasons for this convergence have to do with, first, the increased awareness that effective monitoring of the PRS approach (development strategies in general) and the MDGs require that statistical strategies be embedded into the PRS approach. Second, TA providers in statistics have been increasingly frustrated by the perceived lack of priority for statistical reforms and therefore their funding, as long as national authorities and donors did not see a clear link of such reforms to the national priorities (and priority funding) as defined by the PRS approach or overarching development strategies (for details, see Section V below).

The Second International Roundtable on Managing for Development Results in Morocco endorsed MAPS, but emphasized that weak statistical capacity is still a key constraint to managing for better results in many countries. Thus, the meeting outcome consolidated earlier efforts to formulate statistical development strategies. The drive toward integrating these strategies into the PRS approach is much more evident in the Paris Declaration and the output of the Third International Roundtable in Hanoi. The Paris Declaration on Aid Effectiveness gave greater prominence to ownership, alignment, harmonization, managing for results, and mutual accountability. In fact, most of the 12 agreed indicators of progress and the stated targets for 2010 in these key areas have major implications for mainstreaming statistical strategies into national development strategies, including PRSPs and the MTEF (for details, see Appendix I). ${ }^{16}$

\footnotetext{
${ }^{15}$ STATCAP is a World Bank financing mechanism with a simplified process for project preparation supporting the implementation of a country's NSDS.

${ }^{16}$ Note that the 12 indicators are divided into five categories namely ownership, alignment, harmonization, managing for results, and mutual accountability. If fully implemented, these indicators should mutually
} 
The Hanoi Roundtable meeting drew both on MAPS and the Paris Declaration in focusing on building the LICs' capacity to manage results. As a follow-up, a meeting on Better Data for Development Results was convened in Washington in April 2007. Subsequently, a joint paper by the World Bank, PARIS21, and the United Kingdom's Department for International Development (DFID) on enhanced support for statistical capacity (World Bank and others, 2007) was prepared and discussed at the PARIS21 Steering Committee meeting in Paris in May 2007. A key proposal of this paper is "a new approach that provides incentives for harmonizing donor actions in developing statistics in developing countries, aligning them to meet national needs, and, where appropriate, scaling up those interventions in the context of an effective, well-monitored, predictable program of support.”

Under this approach, statistical activities in a country are viewed as a "sector," encompassing both the central statistics office and the statistical activities of line ministries (such as education and health) and any other unit that contribute to the outputs of the national statistical system. This would thus be equivalent to a "multi-donor sectorwide approach (SWAp), ${ }^{17}$ which builds on existing programs and institutional arrangements rather than creating separate funding and governance arrangements." The SWAp "should ensure that support for statistical capacity building is aligned with partner countries’ priorities as recorded in their national statistical development strategies and supports their overall development program." While the notion of integrating statistics into the PRS approach is not new, this proposal to use the SWAp puts more concrete and practical means toward implementing the idea. There is also a recognition that the successful use of SWAps within the PRS approach, notably for social sectors (especially, education and health), may assist the essential big push for statistics as well. Subsequently, the World Bank and PARIS21 have drafted a concept paper to spell out the details of the systemwide approach for statistics. (See World Bank and PARIS21, 2007.)

Further, under this approach, it is clear that development and statistics strategists have come to a common view that the historically separate but parallel paths to incubating strategies in the two areas need to converge. The mainstreaming of statistical strategies into development strategies can ensure common objectives among donors and partner countries focused on capacity building to strengthen the partner country institutional capacities and make them effective enough to monitor the goals and targets set out in national development priorities.

underpin a well-coordinated PRS framework that simultaneously guide partner country and donor activities to a common goal of reducing poverty in the host country. Concomitantly, all of the partner country's and donor's need for statistics to monitor progress and guide policies in this regard should have been effectively mainstreamed within this PRS framework. Appropriate priority and funding in the MTEF would provide a basis to support sustained reforms.

${ }^{17}$ During the PARIS21 Steering Committee discussions, there was general support to adopt a "systemwide approach” to statistics as opposed to a "sectorwide approach.” 
The approach also provides means through which the integrated developments in poverty reduction and statistics can exploit the synergies while ensuring concomitant progress on all fronts.

\section{Constraints to EfFective Statistical TeChnical Assistance}

As noted above, constraints to the effective TA provision has been another issue contributing to the need to merge statistical and development strategies. In general, LICs lack resources (financial, information technology, and skilled manpower) to design and implement statistical reforms. The issue of resource constraints to statistical capacity-building figures prominently in the DQAF (Appendix II, in particular, element 0.2 and the related issue of source data-element 3.1).

Evidence of the resource constraint on data quality and the need for TA has also emerged in the IMF's surveillance and TA work. The results of the data ROSC missions for LICs eligible for the PRGF of the IMF indicate that resources have indeed been a major factor impeding data quality in these countries (Table 1). Evidently, the most severely impacted sectors are government finance statistics and national accounts, followed by prices and balance of payments. ${ }^{18}$

The problems with government finance statistics may be associated with the trend toward decentralization to improve the provision of public services to the poor and vulnerable, but with inadequate resources to compile the requisite monitoring data from an increased number of agencies and local governments. In many LICs, there has been a decentralization of central government activities to autonomous agencies, many of which have their own resources. Few such countries even correctly identify these agencies as central government, much less collect data on their operations on a regular basis. For instance, there are over 70 such units in Sierra Leone; the Kenya National Bureau of Statistics identifies 83 autonomous agencies of central government; and most other LICs have a similar extent of decentralization. In many LICs, donors insist, for purposes of monitoring, that foreign-funded development projects be implemented by autonomous agencies, thus hugely undermeasuring capital formation in central government. There has been an increase also in the number of local governments as well, and many donors, especially nongovernmental organizations, channel significant resources through these local governments, which are not always able to record and report such operations.

\footnotetext{
${ }^{18}$ Economic liberalization and globalization are leading to the greater need for surveys to generate source data for balance of payments statistics. The abolition of exchange controls in many central banks removed a major access to administrative source data, for which surveys are the alternative means of generating the requisite source data. Moreover, the rapid expansion of services and private financial flows (e.g., remittances and direct investments) require more regular updates of enterprise and other surveys to generate source data.
} 


\section{Table 1. Adequacy of Resources for Statistical Production in PRGF-Eligible Countries}

\begin{tabular}{|c|c|c|}
\hline Dataset $^{1}$ & $\begin{array}{c}\text { Adequate } \\
\text { Resources }^{2}\end{array}$ & $\begin{array}{l}\text { Inadequate } \\
\text { Resources }^{3}\end{array}$ \\
\hline & \multicolumn{2}{|c|}{ Number of Countries } \\
\hline National accounts & 2 & 20 \\
\hline Consumer prices & 3 & 15 \\
\hline Producer prices & 3 & 8 \\
\hline Government finance statistics & 1 & 21 \\
\hline Money and financial statistics & 13 & 8 \\
\hline \multirow[t]{2}{*}{ Balance of payments } & 6 & 16 \\
\hline & \multicolumn{2}{|c|}{ Percent of Total } \\
\hline National accounts & 9.1 & 90.9 \\
\hline Consumer prices & 16.7 & 83.3 \\
\hline Producer prices & 27.3 & 72.7 \\
\hline Government finance statistics & 4.5 & 95.5 \\
\hline Money and financial statistics & 61.9 & 38.1 \\
\hline Balance of payments & 27.3 & 72.7 \\
\hline \multicolumn{3}{|l|}{ Memorandum item: } \\
\hline Weighted average (percent of total) & 24.1 & 75.9 \\
\hline
\end{tabular}

Source: DQAF-based data ROSCs conducted in 22 PRGF-eligible countries since 2001.

${ }^{1}$ In some cases, data ROSCs exclude assessments for certain datasets.

${ }^{2}$ Rating of "Observed" indicates that resources were found to be commensurate with tasks.

${ }^{3}$ Ratings of "Largely Observed," “Largely Not Observed," and “Not Observed” are, respectively, taken to denote: some, significant, and substantial insufficiency.

More generally, other factors affecting the quality of the data compiled to monitor fiscal performance include:

- The methodological framework in which the fiscal data are compiled by many LICs does not meet the current international standard, the Government Finance Statistics

Manual 2001 (GFSM 2001), and the fiscal data are deficient in terms of institutional and transactions coverage (as noted above). They also lack consistency since they do not integrate stocks and flows in an internally consistent framework. Inadequate exposure of compilers and analysts to the methodology of the GFSM 2001 continues to be an impediment to its implementation in LICs. 
- The effective monitoring of a country's ability to achieve the benchmarks of the PRS often requires data that focus on specific government outlays or fiscal data that are broken down by the Classification of Functions of Government (COFOG). Data compiled according to COFOG can yield useful information on the progress over time that a country has made toward meeting specified socioeconomic objectives. In addition, the methodological framework of the COFOG facilitates international comparisons. Given the limited institutional capacity of compiling agencies in LICs, any meaningful effort to strengthen the COFOG databases is resource-intensive and would require the provision of significant levels of technical assistance over an extended period of time.

In summary, at the heart of the inadequate statistics is the low priority and funding for developing the capacity to monitor activities or utilize TA effectively.

An ongoing review of the 10 years of the GDDS ${ }^{19}$ (see Alexander and others, 2007) has made preliminary findings that:

- From the regional analysis, it appears that the problems (GDDS countries' readiness to subscribe to the SDDS) are more pronounced in Africa and the Western Hemisphere. These two regions are the farthest from the SDDS requirement (timeliness and periodicity for data dissemination) in the areas of real and external data;

- Uneven progress across macroeconomic datasets seems to reflect the fact that some datasets, notably for the real and external sectors, rely on expensive and resourceintensive source data. The regional deviation in compliance with the SDDS requirements could be the result of the differences in the availability of resources to absorb capacity-building technical assistance.

The agencies and donors who have stepped into the breach to provide TA in these areas have felt a need to coordinate and assist in mobilizing aid to facilitate effective services in the relevant LICs, including their sustainability. ${ }^{20}$ Indeed, the paucity of enabling resources for statistical reforms is much greater in relative terms compared with other sectors. Notably, the social sectors (in particular, education and health) have garnered donor and partner country priority and are often included in the protected areas within the MTEF. Looking at these

\footnotetext{
${ }^{19}$ To date, 94 countries have participated in the GDDS, 6 of which went on to become subscribers to the SDDS, leaving 88 countries as current participants.

${ }^{20}$ See, for instance, “the Canadian Initiative," including proposals for twinning arrangements by Statistics Canada with a number of developing country statistical offices. For details, see Fellegi, 2006. See also the U.K. White Paper on Eliminating World Poverty (DFID, 2006).
} 
arrangements from the outside, statistical TA providers have attempted to bring their recommended reforms into the PRS approach and the MTEF to provide a measure of assurance for the requisite medium-term funding to initiate and sustain statistical reforms.

The provision of TA for statistical capacity building covers a broad continuum, ranging from strengthening institutions and infrastructure to data quality issues. Donor support for the institutional/infrastructure capacity, covering also censuses, surveys, and administrative data systems, tends to generate sociodemographic statistics, many of which are also source data for macroeconomic datasets, especially prices, national accounts, and balance of payments. The IMF (including the six affiliated regional technical assistance centers- RTACs $^{21}$ ) tends to focus its TA activities on data quality issues. As a niche macroeconomic statistical TA provider, the IMF is more dependent on financial and other inputs by other primary TA providers - donors - to build the essential foundation to make its own TA more effective. ${ }^{22}$

Partly because of the nature (broad range and interdependence of datasets) of TA in statistics and the specialization of its providers and differences among the recipient regions and countries, coordination is critical to effective capacity building. The TA providers have, over time, come around to appreciating the need for requisite collaboration, including through enhanced joint efforts, to help mobilize resources for statistical reforms. Taking a leaf from the experience with the PRS process, which has substantially benefited the social sectors, providers of TA in statistics have come to the conclusion that national priority and funding for statistics could benefit from mainstreaming statistics into the PRS approach and the related MTEF. This is currently viewed as a critical stage in facilitating the effectiveness of TA to promote sustainability of statistical reforms.

The IMF has had a limited experiment with integrating the GDDS plans for improvement into the PRSPs with application in a few African countries. The main reason for the focus on Africa is the relatively greater problem with capacity building and the fact that most of the PRGF-supported programs and, therefore, PRSPs are mostly with African countries. ${ }^{23}$ Since 2002, the IMF and the World Bank have been executing the Anglophone Africa GDDS project funded by DFID (for details, see Appendix III). Early success was achieved with preparing metadata, including plans for statistical improvement, enabling 13 of the original 14 countries participating in the project to join the GDDS. Subsequently, efforts were made to utilize the plans for statistical improvement as a vehicle to provide TA and build the

\footnotetext{
${ }^{21}$ These comprise Central AFRITAC (Gabon), East AFRITAC (Tanzania), West AFRITAC (Mali), CARTAC (Barbados), METAC (Lebanon), and PFTAC (Fiji).

${ }^{22}$ See IMF and World Bank, 2007, especially pp. 2-3.

${ }^{23}$ As of April 2007, there were 17 countries in Africa with PRGF-supported programs out of a total of 28 such programs, while a majority of countries with PRSPs are from Africa.
} 
requisite capacity, but there was no attempt during this period to incorporate these into the PRSP.

More recently, steps have been taken in selected cases to integrate the GDDS plans for improvement into the PRSPs and related MTEF. Sierra Leone was a successful pilot in this regard (IMF, 2005a and IMF, 2005b). While the authorities were able to coordinate efforts necessary to prepare a section in the PRSP on the strategic role of developing a statistical system and a medium-term budget for the requisite reforms, in practice, staff turnover, domestic budgetary constraints, and the fact that donors had not been part of the exercise limited the expected outcome. In 2006, assistance was provided to Zambia to help the authorities and lead donors in statistics to integrate the cost of macroeconomic statistical reforms into the National Development Plan (NDP, 2006-2011); the sociodemographic statistical reforms had already been costed and reflected in the plan and the associated MTEF.

A second phase of the GDDS project (2006-09) was launched in September 2006 in Cape Town, South Africa. Drawing extensively on the experience of the earlier project, the second phase incorporates as its main feature modules for delivering TA through workshops and visits by experts to a small group of target countries with similar capacity shortcomings. There are a total of eight IMF-executed modules, one of which notably assists five countries (Lesotho, Malawi, Seychelles, Sudan, and Zambia) to integrate their GDDS plans for improvement and other statistical reforms into the PRSPs to enhance the priority and funding for such reforms (see Appendix IV). This module is expected to provide more hands-on experience for TA delivery, which could be subsequently applied to other countries.

The IMF has also attempted to work with some Francophone countries to incorporate their GDDS and other plans for statistical reform into the PRSP. TA was provided to Burundi to accomplish a similar outcome. One advantage in Burundi was the fact that the authorities and relevant donors had already costed and prepared comprehensive prioritized reforms for the national statistics agency-Institut de Statistique et des Etudes Economiques du Burundi (ISTEBU). The prototype costing framework for ISTEBU was used by the IMF TA mission as a basis for preparing a costed set of comprehensive reforms covering also the other macroeconomic and sociodemographic datasets (a copy of the template is provided in Appendix V). Assistance was provided to the Democratic Republic of the Congo with incorporating the costed statistical reforms in the PRSP. In 2006, joint missions with PARIS21 assisted the authorities in Burkina Faso and Senegal to integrate their GDDS and other plans for statistical reform into the PRSP and cost them for incorporation in the MTEF.

It is still too early to assess the full impact of these pilot efforts in Africa. Success will require both a greater acceptance of mainstreaming statistics into the PRS approach and a broader participation by donors and, of course, country authorities in the exercise. Practical steps to implement the approach will come with experience, but the first installments have 
been proposed in the joint World Bank PARIS21 paper on the SWAp. Such first steps entail identifying existing good practices and a select group of countries-where SWAps may be appropriate and where more intensive donor effort is needed—to use as pilots. Concrete measures to guide future modification in the PRS approach will be informed by these and other pilot cases discussed above. Meanwhile, the greater advocacy role envisaged by PARIS21 with a SWAp for statistics as a follow-up to the Third Roundtable meeting in Hanoi augers well for future positive development in the effort to enhance statistical capacity building.

\section{REALISTIC BUDGET FOR STATISTICAL REFORMS}

Notwithstanding the case for a more balanced priority in the PRS approach for the development of statistical systems, it is also important that resource claims for statistical reforms incorporate prudence and realism. The proposed scope of statistical reforms should be tempered to fit into the existing environment. An incremental and well-phased design of reforms may also ensure better sustainability than a wholesale introduction of new state-ofthe-art systems. The components and total cost of reforms need to be developed, keeping in mind the overall resource constraint. ${ }^{24}$ The GDDS/NSDS coordinator working with all the statistical agencies and experts in costing the relevant reforms should help to ensure that the funding for the overall reforms in statistics is comprehensive and also appropriately formulated and phased over the period of the PRSP and the MTEF.

Early and continuous coordination with donors and the ministry of finance is key to maintaining feasible reforms' cost proposals in developing the inputs for the MTEF. Inevitably, there will be occasional critical but lumpy projects (e.g., population and housing or agricultural censuses and setting up autonomous national statistical agencies), but with adequate advance timing and phased donor and government support, these projects can be fitted reasonably within the MTEF.

There will inevitably be a learning process, but adopting a systemwide approach to mediumterm budgeting for statistics could emulate the successful practices already employed in social sectors in using annual public expenditure reviews (PERs) to provide regular updates for the MTEF.

\footnotetext{
${ }^{24}$ Experience with some early versions of the NSDS is a case in point, where overly ambitious infrastructural projects and reforms resulted in substantial resource requirements, which were not acceptable to the relevant ministries of finance and donors. Such setbacks proved almost fatal to the worthy need to support statistical reforms and required considerable confidence rebuilding to overcome the initial negative reaction.
} 


\section{CONCLUSIONS}

Since the late 1990s, efforts have converged—by development practitioners, national, donor, and TA providers - to address weak statistical capacity in developing countries within the broader framework of poverty reduction. The introduction of the PRS approach and agreement on the Monterrey Consensus set in motion major changes in the way partner countries, donors, and the other development partners interact in assisting developing countries overcome poverty. They placed greater emphasis on broad participation of the general public in developing countries in having direct inputs in and thus promote national ownership of the overall development strategies with specific objectives (the MDGs) to address poverty.

Donors and other development partners undertook to increase the level of their assistance within a framework that channels these resources through developing country institutions via improved harmonization and accountability, with the aim of enhancing the effectiveness of these financial and TA resources. Separately, but in parallel fashion, efforts were made to develop broad-based statistical strategies to address the very limited institutional capacity, among other things, to meet the substantially increased demand for data to support a greater international effort to reduce poverty and effectively monitor the progress.

Both the success of the PRS approach - the broad international recognition of its potential and donors' willingness to use the framework to coordinate resource mobilization for developing countries, especially the social sector-and its limited progress in generating the requisite monitoring progress for the MDGs and other objectives, have together been the driving forces to further favorable reforms. Mainstreaming statistics into development strategies, notably the PRS approach, is critical to enhancing the national priority and funding for statistical reforms. The approach should be equally beneficial to promoting the effectiveness of TA and speed of adjustment in the partner countries to expedite mutual accountability and monitoring of MDGs-a win-win situation.

There is emerging evidence from operational experience that resources are critical to the effectiveness of TA. Indeed, this is particularly the case for macroeconomic datasets in national accounts, prices, and balance of payments, given their high dependence on source data from surveys and censuses. Resources are a constraint for government finance statistics as well, which may be associated with the trend toward decentralization with limited capacity to compile and disseminate data from autonomous central government agencies and local governments. These outcomes tend to reinforce the emerging concerns that have been expressed in various international fora. Addressing these problems both through increased resources and enhanced coordination among partner country statistical agencies, donors, and other TA providers should be an important, although not necessarily a sufficient, condition for more effective TA. 
The concrete steps to implement the approach proposed in this paper will take time to fully develop. Clearly, advocacy work is still key, given the public good characteristic of statistics - with an evidently significant market failure that has hitherto impeded realization of the full potential of public value for data and monitoring. Building public awareness within the LICs and development partners is still crucial to enhancing priority and therefore funding for statistical development within the PRS approach, including in the MTEF. Comprehensive listing and costing - leading to prioritization of statistical reforms - are also central to the process and will require leadership by partner countries' authorities supported by donors and the IMF. The selection of countries to pilot these endeavors, including the SWAp, should provide best practices to guide future work.

To complement these efforts, statisticians and TA providers in the sector need to formulate comprehensive but realistic reform budgets and are well advised to emulate the annual sector PERs that have proven successful in other PRS sectors.

Perhaps, reflecting its level of economic development, Africa faces a particularly challenging situation, not only in terms of the starting position but also in terms of the relative effort needed to mobilize the requisite resources to support statistical capacity. While the impetus for change needs the support of development partners, success depends crucially on local ownership. The leading role would need to be played by the country authorities, especially policymakers, in ensuring that statistics are fully mainstreamed in the national development priorities and MTEFs to reduce poverty. 


\section{Appendix I. Paris Declaration on Aid Effectiveness: Indicators of Progress} (To be measured nationally and monitored internationally)

\begin{tabular}{|c|c|c|}
\hline \multicolumn{2}{|r|}{ OWNERSHIP } & $\begin{array}{l}\text { TARGETS } \\
\text { FOR } 2010\end{array}$ \\
\hline 1 & $\begin{array}{l}\text { Partners have operational development strategies - Number of countries with } \\
\text { national development strategies (including PRSs) that have clear strategic } \\
\text { priorities linked to a medium-term expenditure framework and reflected in annual } \\
\text { budgets. }\end{array}$ & $\begin{array}{l}\text { At least } 75 \% * \text { of partner } \\
\text { countries }\end{array}$ \\
\hline \multicolumn{2}{|r|}{ A L I G N MENT } & $\begin{array}{l}\text { TARGETS } \\
\text { FOR } 2010\end{array}$ \\
\hline 2 & $\begin{array}{l}\text { Reliable country systems - Number of partner countries that have procurement } \\
\text { and public financial management systems that either (a) adhere to broadly } \\
\text { accepted good practices or (b) have a reform programme in place to achieve } \\
\text { these. }\end{array}$ & $\begin{array}{l}\text { Target for improvement to be } \\
\text { set by September } 2005\end{array}$ \\
\hline 3 & $\begin{array}{l}\text { Aid flows are aligned on national priorities - Percent of aid flows to the } \\
\text { government sector that is reported on partners' national budgets. }\end{array}$ & $\begin{array}{l}85 \% * \text { of aid flows } \\
\text { reported on budgets }\end{array}$ \\
\hline 4 & $\begin{array}{l}\text { Strengthen capacity by co-ordinated support - Percent of donor capacity- } \\
\text { development support provided through co-ordinated programmes consistent with } \\
\text { partners' national development strategies. }\end{array}$ & $\begin{array}{l}\text { Target for improvement to be } \\
\text { set by September } 2005\end{array}$ \\
\hline 5 & $\begin{array}{l}\text { Use of country systems - Percent of donors and of aid flows that use partner } \\
\text { country procurement and/or public financial management systems in partner } \\
\text { countries, which either (a) adhere to broadly accepted good practices or (b) have } \\
\text { a reform programme in place to achieve these. }\end{array}$ & $\begin{array}{l}\text { Target for improvement to be } \\
\text { set by September } 2005\end{array}$ \\
\hline 6 & $\begin{array}{l}\text { Strengthen capacity by avoiding paralle/ implementation structures - Number of } \\
\text { parallel project implementation units (PIUs) per country. }\end{array}$ & $\begin{array}{l}\text { Target for improvement to be } \\
\text { set by September } 2005\end{array}$ \\
\hline 7 & $\begin{array}{l}\text { Aid is more predictable - Percent of aid disbursements released according to } \\
\text { agreed schedules in annual or multi-year frameworks. }\end{array}$ & $\begin{array}{l}\text { At least } 75 \% * \text { of such aid } \\
\text { released on schedule }\end{array}$ \\
\hline 8 & Aid is untied - Percent of bilateral aid that is untied. & Continued progress \\
\hline \multicolumn{2}{|r|}{ HARMONISATION } & $\begin{array}{l}\text { TARGETS } \\
\text { FOR } 2010\end{array}$ \\
\hline 9 & $\begin{array}{l}\text { Use of common arrangements or procedures - Percent of aid provided as } \\
\text { programme-based approaches }{ }^{5}\end{array}$ & At least $25 \% *$ \\
\hline 10 & $\begin{array}{l}\text { Encourage shared analysis - Percent of (a) field missions and/or (b) country } \\
\text { analytic work, including diagnostic reviews that are joint. }\end{array}$ & $\begin{array}{l}\text { Target for improvement to be } \\
\text { set by September } 2005\end{array}$ \\
\hline \multicolumn{2}{|r|}{ MANAGING FOR RESULTS } & $\begin{array}{l}\text { TARGET } \\
\text { FOR } 2010\end{array}$ \\
\hline 11 & $\begin{array}{l}\text { Results-oriented frameworks - Number of countries with transparent and } \\
\text { monitorable performance assessment frameworks to assess progress against (a) } \\
\text { the national development strategies and (b) sector programmes. }\end{array}$ & $75 \%^{*}$ of partner countries \\
\hline \multicolumn{2}{|r|}{ MUTUAL ACCOUNTABILITY } & $\begin{array}{l}\text { TARGET } \\
\text { FOR } 2010\end{array}$ \\
\hline 12 & $\begin{array}{l}\text { Mutual accountability - Number of partner countries that undertake mutual } \\
\text { assessments of progress in implementing agreed commitments on aid } \\
\text { effectiveness including those in this Declaration. }\end{array}$ & $\begin{array}{l}\text { Target for improvement to be } \\
\text { set by September } 2005\end{array}$ \\
\hline
\end{tabular}

* These figures will be confirmed or amended by September 2005.

5 See methodological notes for a definition of programme based approaches.

Source: Paris Declaration on Aid Effectiveness, Paris, February 28-March 2, 2005. 


\section{Appendix II. Data Quality Assessment Framework-Generic Framework (July 2003 Framework)}

\begin{tabular}{|c|c|c|}
\hline Quality Dimensions & Elements & Indicators \\
\hline \multirow[t]{4}{*}{$\begin{array}{l}\text { 0. Prerequisites of } \\
\text { quality }\end{array}$} & $\begin{array}{l}\text { 0.1 Legal and institutional } \\
\text { environment-The environment } \\
\text { is supportive of statistics }\end{array}$ & $\begin{array}{l}\text { 0.1.1 The responsibility for collecting, processing, } \\
\text { and disseminating the statistics is clearly specified. } \\
\text { 0.1.2 Data sharing and coordination among data- } \\
\text { producing agencies are adequate. } \\
0.1 .3 \text { Individual reporters' data are to be kept } \\
\text { confidential and used for statistical purposes only. } \\
0.1 .4 \text { Statistical reporting is ensured through legal } \\
\text { mandate and/or measures to encourage response. }\end{array}$ \\
\hline & $\begin{array}{l}\text { 0.2 Resources-Resources are } \\
\text { commensurate with needs of } \\
\text { statistical programs. }\end{array}$ & $\begin{array}{l}0.2 .1 \text { Staff, facilities, computing resources, and } \\
\text { financing are commensurate with statistical } \\
\text { programs. } \\
0.2 .2 \text { Measures to ensure efficient use of resources } \\
\text { are implemented. }\end{array}$ \\
\hline & $\begin{array}{l}0.3 \text { Relevance-Statistics cover } \\
\text { relevant information on the } \\
\text { subject field. }\end{array}$ & $\begin{array}{l}\text { 0.3.1 The relevance and practical utility of existing } \\
\text { statistics in meeting users’ needs are monitored. }\end{array}$ \\
\hline & $\begin{array}{l}\mathbf{0 . 4} \text { Other quality } \\
\text { management-Quality is a } \\
\text { cornerstone of statistical work. }\end{array}$ & $\begin{array}{l}\text { 0.4.1 Processes are in place to focus on quality. } \\
\text { 0.4.2 Processes are in place to monitor the quality of } \\
\text { the statistical program. } \\
\text { 0.4.3 Processes are in place to deal with quality } \\
\text { considerations in planning the statistical program. }\end{array}$ \\
\hline \multirow{3}{*}{$\begin{array}{l}\text { 1. Assurances of } \\
\text { integrity } \\
\text { The principle of } \\
\text { objectivity in the } \\
\text { collection, } \\
\text { processing, and } \\
\text { dissemination of } \\
\text { statistics is firmly } \\
\text { adhered to. }\end{array}$} & $\begin{array}{l}\text { 1.1 Professionalism-Statistical } \\
\text { policies and practices are } \\
\text { guided by professional } \\
\text { principles. }\end{array}$ & $\begin{array}{l}\text { 1.1.1 Statistics are produced on an impartial basis. } \\
\text { 1.1.2 Choices of sources and statistical techniques } \\
\text { as well as decisions about dissemination are } \\
\text { informed solely by statistical considerations. } \\
\text { 1.1.3 The appropriate statistical entity is entitled to } \\
\text { comment on erroneous interpretation and misuse of } \\
\text { statistics. }\end{array}$ \\
\hline & $\begin{array}{l}\text { 1.2 Transparency-Statistical } \\
\text { policies and practices are } \\
\text { transparent. }\end{array}$ & $\begin{array}{l}\text { 1.2.1 The terms and conditions under which } \\
\text { statistics are collected, processed, and disseminated } \\
\text { are available to the public. } \\
\text { 1.2.2 Internal governmental access to statistics prior } \\
\text { to their release is publicly identified. } \\
\text { 1.2.3 Products of statistical agencies/units are } \\
\text { clearly identified as such. } \\
\text { 1.2.4 Advance notice is given of major changes in } \\
\text { methodology, source data, and statistical techniques. }\end{array}$ \\
\hline & $\begin{array}{l}1.3 \text { Ethical standards-Policies } \\
\text { and practices are guided by } \\
\text { ethical standards. }\end{array}$ & $\begin{array}{l}\text { 1.3.1 Guidelines for staff behavior are in place and } \\
\text { are well known to the staff. }\end{array}$ \\
\hline
\end{tabular}




\begin{tabular}{|c|c|c|}
\hline Quality Dimensions & Elements & Indicators \\
\hline $\begin{array}{l}\text { 2. Methodological } \\
\text { soundness } \\
\text { The methodological } \\
\text { basis for the } \\
\text { statistics follows } \\
\text { internationally } \\
\text { accepted standards, } \\
\text { guidelines, or good } \\
\text { practices. }\end{array}$ & $\begin{array}{l}\text { 2.1 Concepts and definitions-- } \\
\text { Concepts and definitions used } \\
\text { are in accord with } \\
\text { internationally accepted } \\
\text { statistical frameworks. } \\
2.2 \text { Scope-The scope is in } \\
\text { accord with internationally } \\
\text { accepted standards, guidelines, } \\
\text { or good practices. } \\
2.3 \text { Classification/ } \\
\text { sectorization-Classification } \\
\text { and sectorization systems are in } \\
\text { accord with internationally } \\
\text { accepted standards, guidelines, } \\
\text { or good practices. } \\
2.4 \text { Basis for recording-Flows } \\
\text { and stocks are valued and } \\
\text { recorded according to } \\
\text { internationally accepted } \\
\text { standards, guidelines, or good } \\
\text { practices }\end{array}$ & $\begin{array}{l}\text { 2.2.1 The scope is broadly consistent with } \\
\text { internationally accepted standards, guidelines, or } \\
\text { good practices. } \\
\text { 2.3.1 Classification/sectorization systems used are } \\
\text { broadly consistent with internationally accepted } \\
\text { standards, guidelines, or good practices. }\end{array}$ \\
\hline $\begin{array}{l}\text { 3. Accuracy and } \\
\text { reliability } \\
\text { Source data and } \\
\text { statistical techniques } \\
\text { are sound and } \\
\text { statistical outputs } \\
\text { sufficiently portray } \\
\text { reality }\end{array}$ & $\begin{array}{l}\text { 3.3 Statistical techniques-- } \\
\text { Statistical techniques employed } \\
\text { conform to sound statistical } \\
\text { procedures } \\
\text { 3.4 Assessment and validation } \\
\text { of intermediate data and } \\
\text { statistical outputs- } \\
\text { Intermediate results and } \\
\text { statistical outputs are regularly } \\
\text { assessed and validated. } \\
\text { 3.5 Revision studies- } \\
\text { Revisions, as a gauge of } \\
\text { reliability, are tracked and } \\
\text { mined for the information they } \\
\text { may provide. }\end{array}$ & $\begin{array}{l}\text { 3.1.1 Source data are obtained from comprehensive } \\
\text { data collection programs that take into account } \\
\text { country-specific conditions. } \\
\text { 3.1.2 Source data reasonably approximate the } \\
\text { definitions, scope, classifications, valuation, and } \\
\text { time of recording required. } \\
\text { 3.1.3 Source data are timely. } \\
\text { 3.2.1 Source data-including censuses, sample } \\
\text { surveys, and administrative records-are routinely } \\
\text { assessed, e.g., for coverage, sample error, response } \\
\text { error, and nonsampling error; the results of the } \\
\text { assessments are monitored and made available to } \\
\text { guide statistical processes. } \\
\text { 3.3.1 Data compilation employs sound statistical } \\
\text { techniques to deal with data sources. } \\
\text { 3.3.2 Other statistical procedures (e.g., data } \\
\text { adjustments and transformations, and statistical } \\
\text { analysis) employ sound statistical techniques. } \\
\text { 3.4.1 Intermediate results are validated against other } \\
\text { information where applicable. } \\
\text { 3.4.2 Statistical discrepancies in intermediate data } \\
\text { are assessed and investigated. } \\
\text { 3.4.3 Statistical discrepancies and other potential } \\
\text { indicators or problems in statistical outputs are } \\
\text { investigated. } \\
\text { 3.5.1 Studies and analyses of revisions are carried } \\
\text { out routinely and used internally to inform statistical } \\
\text { processes (see also 4.3.3). }\end{array}$ \\
\hline
\end{tabular}




\begin{tabular}{|c|c|c|}
\hline Quality Dimensions & Elements & Indicators \\
\hline $\begin{array}{l}\text { 4. Serviceability } \\
\text { Statistics, with } \\
\text { adequate periodicity } \\
\text { and timeliness, are } \\
\text { consistent and } \\
\text { follow a predictable } \\
\text { revisions policy. }\end{array}$ & $\begin{array}{l}\text { 4.1 Periodicity and } \\
\text { timeliness-Periodicity and } \\
\text { timeliness follow internationally } \\
\text { accepted dissemination } \\
\text { standards. } \\
\text { 4.2 Consistency-Statistics are } \\
\text { consistent within the dataset, } \\
\text { over time, and with major } \\
\text { datasets. } \\
\text { 4.3 Revision policy and } \\
\text { practice-Data revisions follow } \\
\text { a regular and publicized } \\
\text { procedure. }\end{array}$ & $\begin{array}{l}\text { 4.2.1 Statistics are consistent within the dataset. } \\
\text { 4.2.2 Statistics are consistent or reconcilable over a } \\
\text { reasonable period of time. } \\
\text { 4.2.3 Statistics are consistent or reconcilable with } \\
\text { those obtained through other data sources and/or } \\
\text { statistical frameworks. } \\
\text { 4.3.1 Revisions follow a regular and transparent } \\
\text { schedule. } \\
\text { 4.3.2 Preliminary and/or revised data are clearly } \\
\text { identified. } \\
\text { 4.3.3 Studies and analyses of revisions are made } \\
\text { public (see also 3.5.1). }\end{array}$ \\
\hline $\begin{array}{l}\text { 5. Accessibility } \\
\text { Data and metadata } \\
\text { are easily available } \\
\text { and assistance to } \\
\text { users is adequate. }\end{array}$ & $\begin{array}{l}5.1 \text { Data accessibility- } \\
\text { Statistics are presented in a } \\
\text { clear and understandable } \\
\text { manner, forms of dissemination } \\
\text { are adequate, and statistics are } \\
\text { made available on an impartial } \\
\text { basis. }\end{array}$ & $\begin{array}{l}\text { 5.1.1 Statistics are presented in a way that facilitates } \\
\text { proper interpretation and meaningful comparisons } \\
\text { (layout and clarity of text, tables, and charts). } \\
\text { 5.1.2 Dissemination media and format are adequate. } \\
\text { 5.1.3 Statistics are released on a preannounced } \\
\text { schedule. } \\
\text { 5.1.4 Statistics are made available to all users at the } \\
\text { same time. } \\
\text { 5.1.5 Statistics not routinely disseminated are made } \\
\text { available upon request. } \\
\text { 5.2.1 Documentation on concepts, scope, } \\
\text { classifications, basis of recording, data sources, and } \\
\text { statistical techniques is available, and differences } \\
\text { from internationally accepted standards, guidelines, } \\
\text { or good practices are annotated. } \\
\text { 5.2.2 Levels of detail are adapted to the needs of the } \\
\text { intended audience. } \\
\text { 5.3.1 Contact points for each subject field are } \\
\text { publicized. } \\
\text { 5.3.2 Catalogs of publications, documents, and other } \\
\text { services, including information on any charges, are } \\
\text { widely available. }\end{array}$ \\
\hline
\end{tabular}




\section{Appendix III. GDDS-Anglophone Africa DFID Project}

The General Data Dissemination System (GDDS) project for Anglophone African countries is sponsored by DFID and executed jointly by the IMF and the World Bank. It supports participating countries in improving the quality of key macroeconomic and sociodemographic statistics to enhance the capacity of national statistical systems. Its development objective is to ensure a more effective design, implementation, and monitoring of macroeconomic policy and poverty reduction strategies. The first phase of the project (2001-2006), involved 15 countries, namely; Botswana, Eritrea, Ethiopia, Ghana, Kenya, Lesotho, Liberia, Malawi, Namibia, Nigeria, Sierra Leone, Sudan, Swaziland, Zambia, and Zimbabwe. The GDDS addresses three key areas: quality of data; development plans for a statistical system, giving a detailed diagnosis of the current situation and an elaborate plan, which identifies the inputs and actions required, and tracking progress of these plans; and dissemination of data. During this period, countries effectively made use of technical assistance provided under the project. Among other things, the project helped to promote closer contact and coordination among agencies engaged in producing statistics. Most of the countries held GDDS workshops to bring together users and providers of statistics to discuss both technical and development issues. These workshops proved useful forums for raising awareness of the importance of statistics and the value of metadata. One key feature of the project was the regional approach, which also proved valuable in promoting regional cooperation and sharing experience between countries through southsouth cooperation.

Following overwhelming endorsement by participating countries to continue the project to ensure the sustainability of progress and achievements attained, DFID generously agreed to sponsor an expanded successor project, namely, the "GDDS Project Phase 2: Modules for Strengthening Statistics,” for the period 2006-2009. The project was expanded to include seven more countries, namely: The Gambia, Mauritius, Mozambique, Seychelles, South Africa, Tanzania, and Uganda. The project will continue to help participating countries to introduce internationally accepted methodologies and good practices. It focuses on results and regional interaction by offering defined technical assistance modules, which can be planned, implemented, and assessed in a coordinated manner. This approach allows sustained capacity building through measurable improvements in agreed areas (modules), and assures mutual commitment to results and ownership both from the participating countries and the providers of technical assistance. Technical assistance delivery, which is results-driven, includes expert visits, hands-on training, and country group workshops to share experiences and learn best practices. The project continues to encourage countries to align the activities to national priorities and enhance coordination and effective use of intra-agency arrangements. It works closely with subregional and regional agencies to ensure enhanced interaction and collaboration. In the countries, it also works closely with other TA providers in statistics. 


\section{Appendix IV. GDDS/PRSP Module: Improving Planning and Execution of Statistical Reforms Using the GDDS ${ }^{25}$}

Expected output: A medium-term revolving plan for improvement in statistics

- $\quad$ Integrated with the General Data Dissemination System (GDDS) plans for improvement, which are posted on the IMF's Dissemination Standards Bulletin Board (DSBB).

- $\quad$ Integrated into the Poverty Reduction Strategy Paper (PRSP), Statistical Master Plan (SMP), National Strategy for Development of Statistics (NSDS), and/or other committed, funded multiyear statistical improvement program.

- $\quad$ Facilitating the monitoring of the PRS and supporting national policymaking through the enhancement of data transparency by disseminating the data on a national website and developing an advance release calendar.

\section{Context and purpose of the module}

African countries are increasingly enjoying better access to technical assistance resources from national governments as well as providers, such as the DFID and the aid agencies of other countries, the AfDB, PARIS21, and the World Bank, but often lack a framework for negotiating a committed, funded statistical business plan having a good chance of execution over the medium term. Committed, funded multiyear statistical plans require an agreement between the government and TA providers as a group on the objectives and the broad modalities by which they will be achieved, consistent with the PRS or comprehensive national development plan. Such negotiated plans may attract technical assistance resources and funding because they make a good business argument for the measures they propose. These arguments are further supported by enhancing data transparency through the dissemination of data on the internet.

This module therefore focuses on:

1. Developing a good plan for statistics within an enhanced GDDS plans for improvement framework that enjoys support from decision makers in national governments and from external providers of technical and financial resources.

2. Creating a national data page available for use by national governments, other policymakers, and external providers of technical and financial resources and an advance release calendar.

\footnotetext{
${ }^{25}$ The GDDS/PRSP module is one of eight modules executed by the IMF (the World Bank is also implementing eight modules) as part of the GDDS project (see Appendix III). Countries participating in the GDDS/PRSP module are Lesotho, Malawi, Seychelles, Sudan, and Zambia.
} 


\section{Capacity requirements for participating countries}

Revolving plans for improvement require:

1. A description and periodic update of the existing state of affairs; and

2. A set of planned tasks collectively achieving a set of well-defined objectives.

Internet-based data dissemination requires:

1. An agency website;

2. A structured data page; and

3. A coordinating agency/body to ensure the timely update of the website.

Technical staff_-statisticians (or economists) having technical and methodological knowledge - are required to draft and update GDDS metadata. Statistical agency managers are required to negotiate, with the assistance, as needed, of the module manager and consultants, overall objectives with government decision makers and external providers of funding and assistance. The statisticians and economists participate in this process by working out the steps (plans for improvement) each reform scenario requires. The metadata are the product of a one-time periodic process, but, as the product of a negotiation, the process of developing plans for improvement is iterative. The website initiative needs support from local IT specialists.

\section{Planned execution of the module}

The module will start with a regional workshop, planned for May 2007, which will provide

- An overview of the elements of the new GDDS developmental framework and the enhanced GDDS plans for improvement.

- An overview of linkages between the enhanced GDDS plans for improvement and the World Bank's SMP and PARIS21's NSDS.

- A stylized process of designing and updating the statistical business plan while negotiating its funding over the medium term through multilateral meetings including statistical agencies and external providers of assistance and funding.

- An opportunity for participants to discuss the advantages of data transparency and the use of the internet to disseminate data as a service to the public.

In the next phase, countries will receive technical assistance missions to help in addressing the priority issues identified in the workshop. The module manager for the GDDS/PRSP 
module will organize technical assistance to update GDDS plans for improvement in consultation with the government and to create a publicly available set of data along with advance notice on when these data will be released. The end product is a set of data available on the Internet to monitor the progress in the PRS, support national policymaking, and GDDS plans for improvement owned by the country, with the understanding and concurrence of external providers, that is "in the critical path" of the process for monitoring and evaluation of project execution. The plans move into the critical path through, for example, incorporation into the medium-term public expenditure plan, the PRSP, and the SMP, as these are prerequisites for various types of statistical program financing.

Two or three missions per country are the norm in this module. The module will benefit from commonality between countries, so that experiences from one can be applied to another, both through the technical assistance mission and through direct contact between country agencies.

A closing workshop will be held at the end of the module, confirming the achievement of the planned outputs and identifying common problems. The workshop will conclude with countries discussing future improvements. 
Appendix V. Template for Costing and Integrating a Statistical Development Action Plan into the MTEF

\begin{tabular}{|c|c|c|c|c|c|c|c|c|c|c|c|c|c|c|c|c|c|c|c|c|c|}
\hline \multirow[b]{3}{*}{$\begin{array}{l}\text { Statistical } \\
\text { sector }\end{array}$} & \multirow[b]{3}{*}{$\begin{array}{l}\text { Data categories/ governmental } \\
\text { agencies }\end{array}$} & \multicolumn{5}{|c|}{ Cost } & \multicolumn{5}{|c|}{ Internal Financing } & \multicolumn{5}{|c|}{ External Financing } & \multicolumn{5}{|c|}{ Financing Gap } \\
\hline & & \multicolumn{5}{|c|}{$\begin{array}{c}\text { (In thousands of } \\
\text { U.S. dollars) }\end{array}$} & \multicolumn{5}{|c|}{ (National Budget) } & \multicolumn{5}{|c|}{$\begin{array}{c}\text { (Aggregate of Donors' } \\
\text { Contributions) }\end{array}$} & \multicolumn{5}{|c|}{$\begin{array}{c}\text { (= Cost - Internal } \\
\text { Financing - External } \\
\text { Financing) }\end{array}$} \\
\hline & & $\begin{array}{l}2 \\
0 \\
0 \\
6 \\
\end{array}$ & $\begin{array}{l}2 \\
\mathbf{0} \\
\mathbf{0} \\
7\end{array}$ & $\begin{array}{l}2 \\
\mathbf{0} \\
\mathbf{0} \\
\mathbf{8}\end{array}$ & $\begin{array}{l}2 \\
0 \\
0 \\
9\end{array}$ & Total & $\begin{array}{l}2 \\
0 \\
0 \\
6\end{array}$ & $\begin{array}{l}2 \\
\mathbf{0} \\
\mathbf{0} \\
7\end{array}$ & $\begin{array}{l}2 \\
0 \\
0 \\
8 \\
\end{array}$ & $\begin{array}{l}2 \\
\mathbf{0} \\
\mathbf{0} \\
\mathbf{9}\end{array}$ & Total & $\begin{array}{l}2 \\
0 \\
0 \\
6\end{array}$ & $\begin{array}{l}2 \\
\mathbf{0} \\
\mathbf{0} \\
7 \\
\end{array}$ & $\begin{array}{l}2 \\
\mathbf{0} \\
\mathbf{0} \\
\mathbf{8} \\
\end{array}$ & $\begin{array}{l}2 \\
\mathbf{0} \\
\mathbf{0} \\
\mathbf{9} \\
\end{array}$ & Total & $\begin{array}{l}2 \\
0 \\
0 \\
6\end{array}$ & $\begin{array}{l}2 \\
\mathbf{0} \\
\mathbf{0} \\
7 \\
\end{array}$ & $\begin{array}{l}2 \\
\mathbf{0} \\
\mathbf{0} \\
\mathbf{8} \\
\end{array}$ & $\begin{array}{l}2 \\
\mathbf{0} \\
\mathbf{0} \\
\mathbf{9} \\
\end{array}$ & Total \\
\hline \multirow{21}{*}{ Real } & National accounts & 0 & 0 & 0 & 0 & 0 & 0 & 0 & 0 & 0 & 0 & 0 & 0 & 0 & 0 & 0 & 0 & 0 & 0 & 0 & 0 \\
\hline & Industrial production index & 0 & 0 & 0 & 0 & 0 & 0 & 0 & 0 & 0 & 0 & 0 & 0 & 0 & 0 & 0 & 0 & 0 & 0 & 0 & 0 \\
\hline & Manufacturing & 0 & 0 & 0 & 0 & 0 & 0 & 0 & 0 & 0 & 0 & 0 & 0 & 0 & 0 & 0 & 0 & 0 & 0 & 0 & 0 \\
\hline & Primary commodity & 0 & 0 & 0 & 0 & 0 & 0 & 0 & 0 & 0 & 0 & 0 & 0 & 0 & 0 & 0 & 0 & 0 & 0 & 0 & 0 \\
\hline & Agricultural & 0 & 0 & 0 & 0 & 0 & 0 & 0 & 0 & 0 & 0 & 0 & 0 & 0 & 0 & 0 & 0 & 0 & 0 & 0 & 0 \\
\hline & Price indices & 0 & 0 & 0 & 0 & 0 & 0 & 0 & 0 & 0 & 0 & 0 & 0 & 0 & 0 & 0 & 0 & 0 & 0 & 0 & 0 \\
\hline & Consumer price index & 0 & 0 & 0 & 0 & 0 & 0 & 0 & 0 & 0 & 0 & 0 & 0 & 0 & 0 & 0 & 0 & 0 & 0 & 0 & 0 \\
\hline & Producer price index & 0 & 0 & 0 & 0 & 0 & 0 & 0 & 0 & 0 & 0 & 0 & 0 & 0 & 0 & 0 & 0 & 0 & 0 & 0 & 0 \\
\hline & Labor market indicators & 0 & 0 & 0 & 0 & 0 & 0 & 0 & 0 & 0 & 0 & 0 & 0 & 0 & 0 & 0 & 0 & 0 & 0 & 0 & 0 \\
\hline & Employment & 0 & 0 & 0 & 0 & 0 & 0 & 0 & 0 & 0 & 0 & 0 & 0 & 0 & 0 & 0 & 0 & 0 & 0 & 0 & 0 \\
\hline & Unemployment & 0 & 0 & 0 & 0 & 0 & 0 & 0 & 0 & 0 & 0 & 0 & 0 & 0 & 0 & 0 & 0 & 0 & 0 & 0 & 0 \\
\hline & Wages/salaries & 0 & 0 & 0 & 0 & 0 & 0 & 0 & 0 & 0 & 0 & 0 & 0 & 0 & 0 & 0 & 0 & 0 & 0 & 0 & 0 \\
\hline & Public sector operations & 0 & 0 & 0 & 0 & 0 & 0 & 0 & 0 & 0 & 0 & 0 & 0 & 0 & 0 & 0 & 0 & 0 & 0 & 0 & 0 \\
\hline & Budgetary central government & 0 & 0 & 0 & 0 & 0 & 0 & 0 & 0 & 0 & 0 & 0 & 0 & 0 & 0 & 0 & 0 & 0 & 0 & 0 & 0 \\
\hline & Extrabudgetary agencies & 0 & 0 & 0 & 0 & 0 & 0 & 0 & 0 & 0 & 0 & 0 & 0 & 0 & 0 & 0 & 0 & 0 & 0 & 0 & 0 \\
\hline & Social security & 0 & 0 & 0 & 0 & 0 & 0 & 0 & 0 & 0 & 0 & 0 & 0 & 0 & 0 & 0 & 0 & 0 & 0 & 0 & \\
\hline & Consolidated central government & & & & & & & & & & & & & & & & & & & & \\
\hline & State governments & 0 & 0 & 0 & 0 & 0 & 0 & 0 & 0 & 0 & 0 & 0 & 0 & 0 & 0 & 0 & 0 & 0 & 0 & 0 & 0 \\
\hline & Local governments & 0 & 0 & 0 & 0 & 0 & 0 & 0 & 0 & 0 & 0 & 0 & 0 & 0 & 0 & 0 & 0 & 0 & 0 & 0 & 0 \\
\hline & Nonfinancial public sector & 0 & 0 & 0 & 0 & 0 & 0 & 0 & 0 & 0 & 0 & 0 & 0 & 0 & 0 & 0 & 0 & 0 & 0 & 0 & \\
\hline & Public sector & 0 & 0 & 0 & 0 & 0 & 0 & 0 & 0 & 0 & 0 & 0 & 0 & 0 & 0 & 0 & 0 & 0 & 0 & 0 & 0 \\
\hline
\end{tabular}




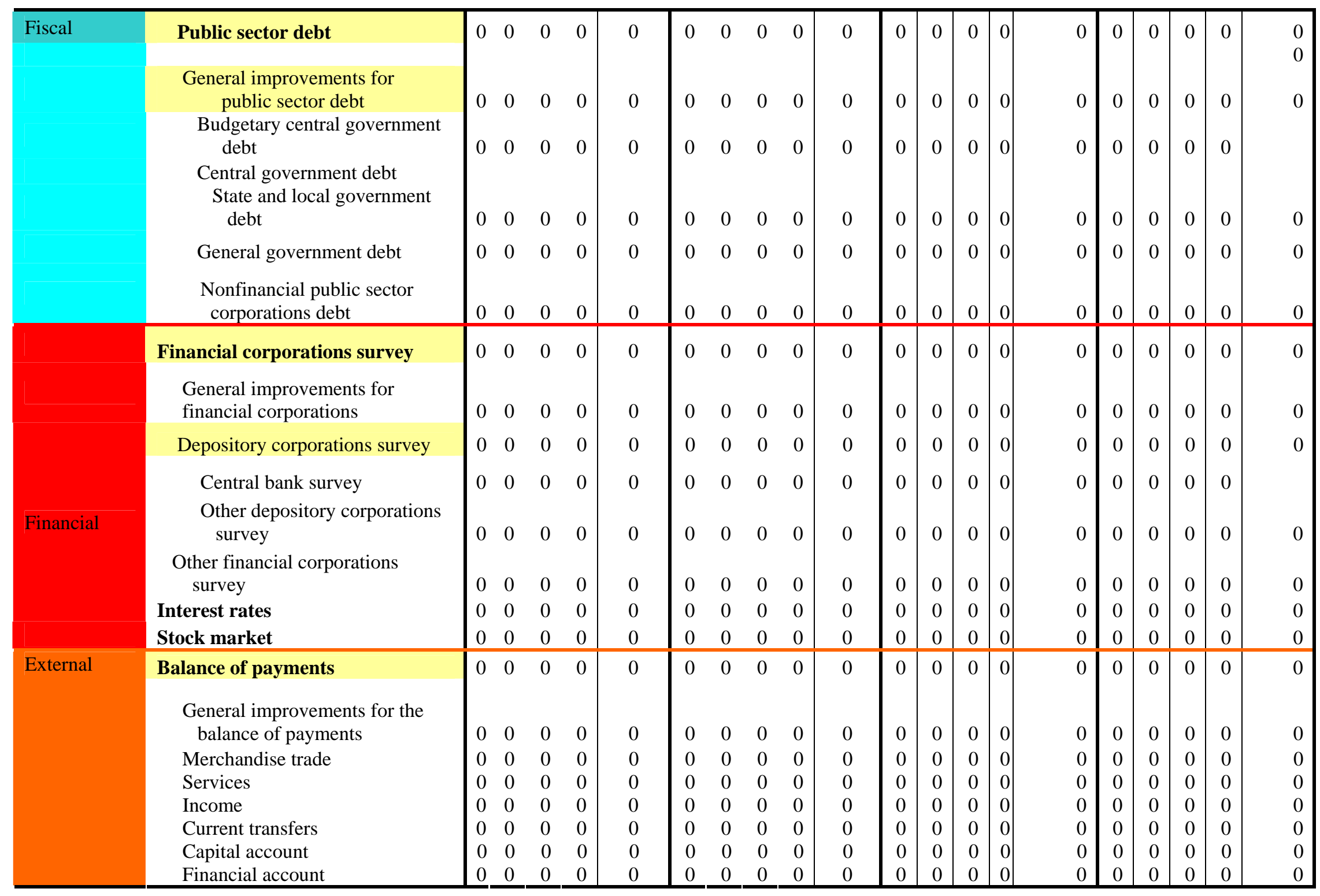




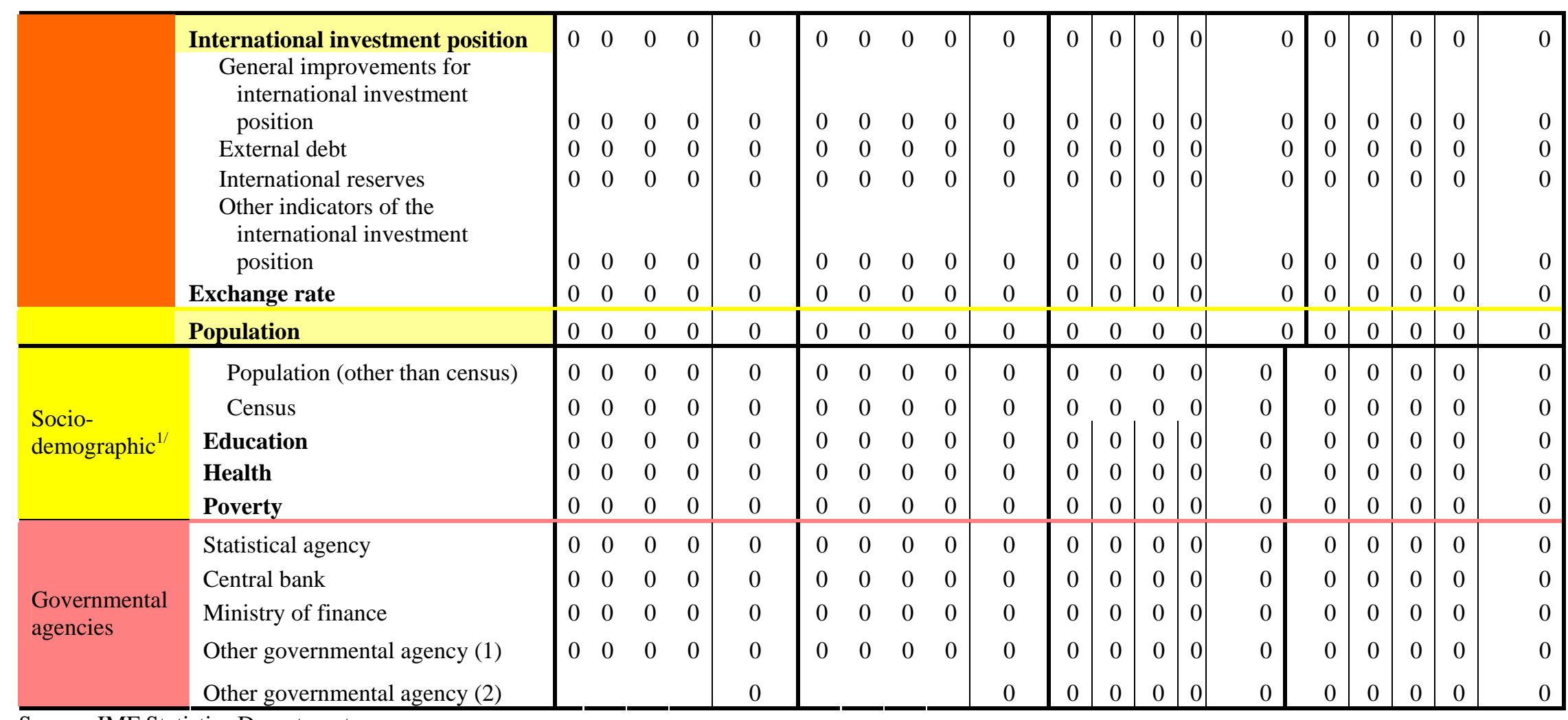

Source: IMF Statistics Department.

${ }^{1 /}$ The coverage of sociodemographic statistics is limited but can easily be expanded to provide more sectors and/or more detailed coverage within the sectors. 


\section{References}

Alexander, William, E., Forthcoming 2007, Theo Bikoi, Claudia Dziobek, Artak Harutyunyan, and Louis Venter, “Assessing the General Data Dissemination System (GDDS) - What Has Been Accomplished After Ten Years, and Where Do We Go From Here?,” (Forthcoming, Washington: International Monetary Fund).

Bedi, Tara, 2006, Aline Coudouel, Marcus Cox, Markus Goldstein, and Nigel Thornton, "Beyond the Numbers, Understanding the Institutions for Monitoring Poverty Reduction Strategies,” (Washington: The World Bank).

de Rato, Rodrigo, 2006, “Renewing the IMF’s Commitment to Low-Income Countries” (Washington).

Fellegi, Ivan, 2006, “Statistical Capacity Building in Developing Countries,” a PowerPoint presentation (Ottawa: Statistics Canada).

International Monetary Fund, 1997, “The General Data Dissemination System,” (Washington).

-----, 1999, “Poverty Reduction and Growth Facility—Operational Issues,” (Washington).

-----, 2003, “Statistics Department Data Quality Assessment Framework (DQAF)” (Washington). Available at http://dsbb.imf.org.

-----, 2005a, "Sierra Leone-Sixth Review Under the Poverty Reduction and Growth Facility, Request for Waiver of Performance Criteria and Additional Interim Assistance Under the Enhanced Initiative for Heavily Indebted Poor Countries, Review of Financing Assurances, and Ex Post Assessment of Longer-Term Program Engagement”. (Washington).

-----, 2005b, “Sixth Review of the Fund’s Data Standards Initiative,” (Washington).

-----, 2005c, “The Managing Director’s Report on the Fund’s Medium-Term Strategy” (Washington).

-----, 2006a, “The Managing Director’s Report on Implementing the Fund’s Medium-Term Strategy" (Washington).

-----, 2006b, “Implementing the Fund’s Medium-Term Strategy_Working Groups’ Reports” (Washington).

-----, 2007a, “Staff Guidance Note on the Application of the Joint Fund-Bank Debt Sustainability Framework for Low-Income Countries” (Washington).

-----, 2007b, “Aid Inflows-The Role of the Fund and Operational Issues for Program Design” (Washington). 
-----, 2007c, “The System of Macroeconomic Accounts Statistics” (Washington).

----- and the World Bank, 2005, "2005 Review of the Poverty Reduction Strategy Approach:

Balancing Accountability and Scaling Up Results,” (Washington).

-----, 2007, “Enhancing Collaboration: Joint Management Action Plan” (Washington), forthcoming.

International Monetary Fund Independent Evaluation Office, 2004, "Evaluation of the IMF's Role in Poverty Reduction and Growth Facility (PRGF)," (Washington).

PARIS21, 2004, "National Strategy for the Development of Statistics (NSDS) Essential," (Paris).

U.K. Department for International Development, 2006, "Eliminating World Poverty, Making Governance Work for the Poor,” (London).

World Bank, 2004, "Better Data for Better Results, An Action Plan for Improving Development Statistics,” (Washington).

World Bank and GTZ (Deutsche Gesselschaft für technische Zusammenarbeit—German Technical Cooperation), 2007, "Minding the Gaps, Integrating Poverty Reduction Strategies and Budgets for Domestic Accountability,” (Washington).

World Bank and PARIS21, 2007, "Scaling Up Investment in National Statistical Systems," (Washington). 